\title{
Assessing the Performance of Residential Energy Management Control Algorithms: Multi-Criteria Decision Making Using the Analytical Hierarchy Process
}

\author{
Farhad Omar \\ Steven T. Bushby \\ Ronald D. Williams
}




\title{
Assessing the Performance of Residential Energy Management Control Algorithms: Multi-Criteria Decision Making Using the Analytical Hierarchy Process
}

\author{
Farhad Omar \\ Steven T. Bushby \\ Energy and Environment Division \\ Engineering Laboratory \\ Ronald D. Williams \\ Department of Electrical and Computer Engineering \\ University of Virginia
}

This publication is available free of charge from:

https://doi.org/10.6028/NIST.TN.2017r1

June 2019

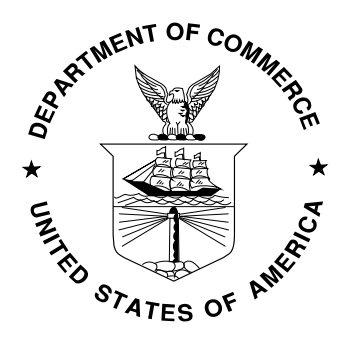

U.S. Department of Commerce Wilbur L. Ross, Jr., Secretary

National Institute of Standards and Technology Walter Copan, NIST Director and Undersecretary of Commerce for Standards and Technology 
Certain commercial entities, equipment, or materials may be identified in this document in order to describe an experimental procedure or concept adequately. Such identification is not intended to imply recommendation or endorsement by the National Institute of Standards and Technology, nor is it intended to imply that the entities, materials, or equipment are necessarily the best available for the purpose.

National Institute of Standards and Technology Technical Note 2017 Revision 1 Natl. Inst. Stand. Technol. Tech. Note 2017 Rev. 1, 39 pages (June 2019) CODEN: NTNOEF

This publication is available free of charge from: https://doi.org/10.6028/NIST.TN.2017r1 


\begin{abstract}
For homes to become active participants in a smart grid, intelligent control algorithms are needed to facilitate autonomous interactions that take homeowner preferences into consideration. Many control algorithms for demand response have been proposed in the literature. Comparing the performance of these algorithms has been difficult because each algorithm makes different assumptions or considers different scenarios, i.e., peak load reduction or minimizing cost in response to the variable price of electricity. This work proposes a flexible assessment framework using the Analytical Hierarchy Process to compare and rank residential energy management control algorithms. The framework is a hybrid mechanism that derives a ranking from a combination of subjective user input representing preferences, and objective data from the algorithm performance related to energy consumption, cost and comfort. The Analytical Hierarchy Process results in a single overall score used to rank the alternatives. The approach is illustrated by applying the assessment process to six residential energy management control algorithms.
\end{abstract}

\title{
Note on Revision
}

An error in the algorithm that maps simulation results to the AHP's Fundamental Scale of Pairwise Comparisons (Table 1) was corrected in Section 7. This correction resulted in small changes to the scoring of the example algorithms (Table 14, Table 15, and Figure 10). Due to the corrections in the mapping algorithm, the sensitivity analysis was no longer relevant and was removed.

\section{Key words}

AHP; Analytical Hierarchy Process; assessment of control algorithms; assessment; assessment and ranking; assessment engine; energy management control algorithms; MADA; multi attribute decision making; MCDM; multi criteria decision making; performance assessment; ranking; residential control algorithms. 


\section{Table of Contents}

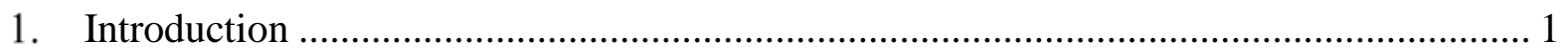

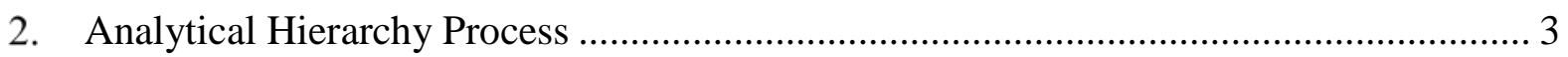

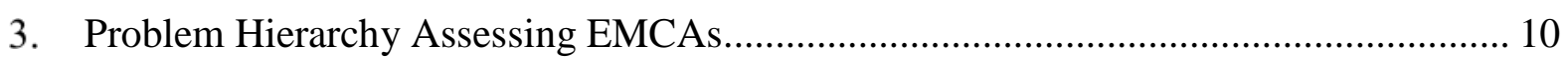

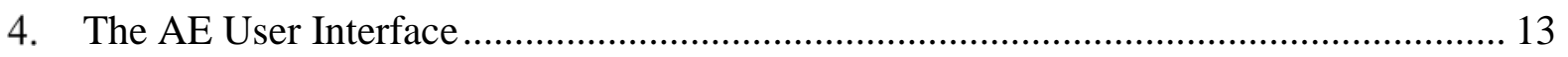

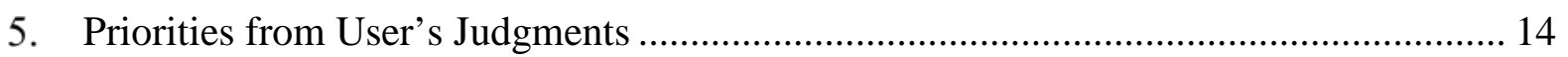

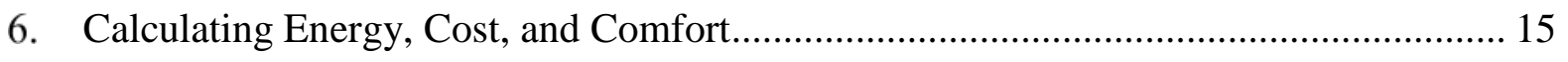

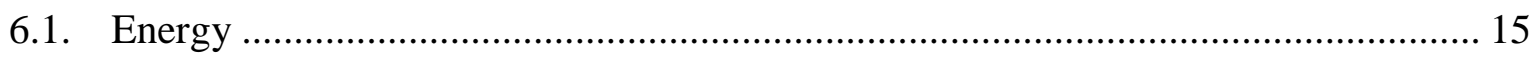

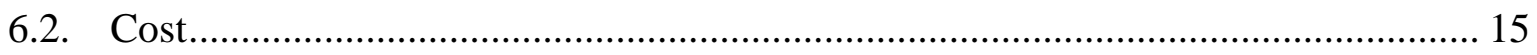

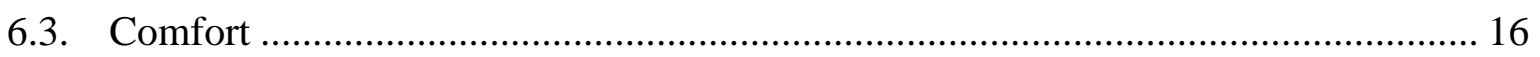

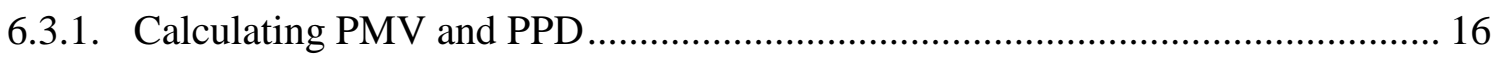

6.3.2. Calculating the Discomfort Index .................................................................... 19

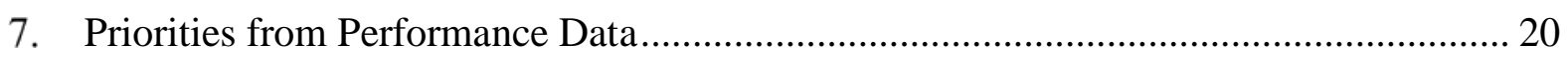

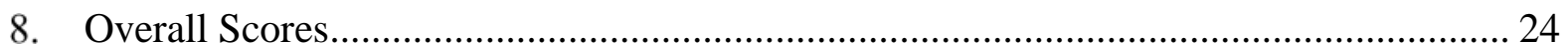

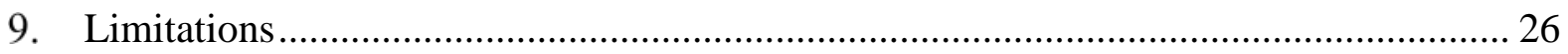

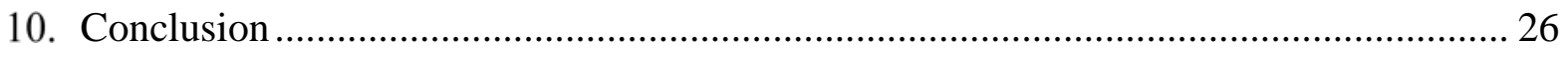

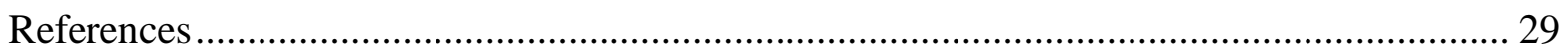




\section{List of Tables}

Table 1. The AHP Fundamental Scale, Adapted from Table 3-1 p. 54 of [21] ...................... 5

Table 2. Criteria compared with respect the Goal for purchasing a house ............................ 5

Table 3. Alternatives compared with respect the criterion Size ............................................ 6

Table 4. The Average RI for Matrices of Order 1-15, Adopted from p. 21of [21] ................. 7

Table 5. The overall scores of alternatives for purchasing a house ..................................... 9

Table 6. Summary Description of Residential EMCAs................................................. 11

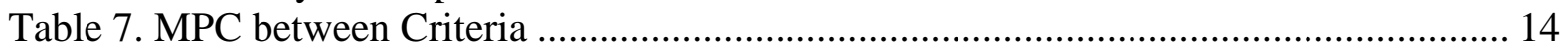

Table 8. Priorities and Consistency metrics.................................................................. 14

Table 9. Seven-point Thermal Sensation Scale .............................................................. 17

Table 10. Assumed Values for Calculating PMV ........................................................... 17

Table 11. The PMV and PPD Ranges for Thermal Comfort .............................................. 19

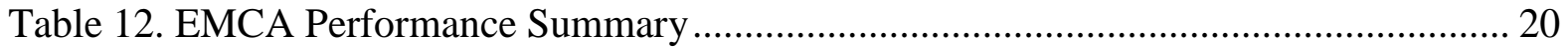

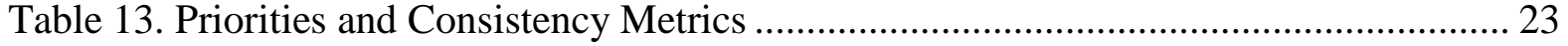

Table 14. Priorities and Consistency Metrics ............................................................... 24

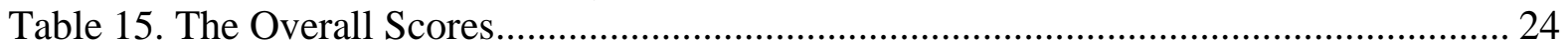

Table 16. MPC for Capturing User Preferences .......................................................... 26

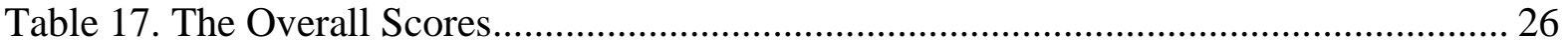




\section{List of Figures}

Figure 1. A schematic representation of the assessment process........................................ 3 Figure 2. Decomposition of the hypothetical problem of purchasing a house into a hierarchy 4 Figure 3. Summary figure showing the relationship between alternatives, criteria, and the goal using priorities for one alternative....

Figure 4 . The assessment problem hierarchy showing the relationship of the alternatives to the criteria and the goal....

Figure 5. The exterior of the NZERTF on the campus of NIST in Gaithersburg, MD ......... 12

Figure 6. The AE user interface captures user's input, loads performance data, and performs

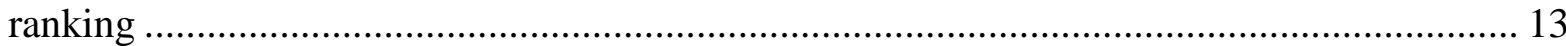

Figure 7. User's Input fields capturing preferences between criteria................................... 14

Figure 8. The hourly RTP tariff used to compute the cost of energy consumption................ 16

Figure 9. Annual comfort results for residential EMCA1 as measured by PMV and PPD.... 19 Figure 10. Summary figure showing the problem hierarchy, priorities and the overall scores for each alternative with respect to the goal ................................................................. 25 


\section{Acronyms}

assessment engine

AE user interface

Analytical Hierarchy Process

American National Standards Institute

American Society of Heating, Refrigerating, and Air-Conditioning Engineers

American Society for Testing and Materials

consistency index

consistency ratio

comparison scale

division by maximum

division by sum

demand response

Energy Information Administration

Energy Independence and Security Act

energy management control algorithm

fault detection and diagnostics

heating, ventilating, and air-conditioning

Institute of Electrical and Electronics Engineers

independent system operators

International Organization for Standardization

kilowatt hour

Matrix Laboratory

mapping cost

multi-criteria decision-making

mapping discomfort

mapping energy consumption

matrix of pairwise comparisons

National Institute of Standards and Technology

Net-Zero Energy Residential Test Facility

Pennsylvania-New Jersey-Maryland Interconnection

predicted mean vote

predicted percentage of dissatisfied

PPD-Weighted criterion

cost ratio

discomfort ratio

energy ratio

random index

regional transmission organizations

real-time pricing

cost scale factor

discomfort scale factor

energy scale factor

Transient System Simulation Tool

Yet Another Linear Matrix Inequalities Parser 


\section{Introduction}

The current electric grid is an essential part of our daily lives. Despite its success, it is under strain from ever-increasing demand and aging infrastructure. In 2016, residential buildings consumed $38 \%$ of the all electricity sold in the U.S. [1]. Space heating, and cooling accounted for $24 \%$ of the electricity consumption in residential buildings [2]. The Energy Independence and Security Act of 2007 (EISA) established a national policy to support the modernization of the national electric grid to maintain a reliable and secure electricity infrastructure that can meet future growth [3]. The vision of a modern, smart electric grid, is "a modernized grid that enables bidirectional flows of energy and uses two-way communication and control capabilities that will lead to an array of new functionalities and applications” [4].

According to Title XIII of EISA [3] a few key characteristics of a smart grid include:

1. "Increased use of digital information and controls technology to improve reliability, security, and efficiency of the electric grid;

2. Development and incorporation of demand response, demand-side resources, and energy-efficiency resources;

3. Deployment of "smart" technologies (real-time, automated, interactive technologies that optimize the physical operation of appliances and consumer devices) for metering, communications concerning grid operations and status, and distribution automation; and

4. Integration of "smart” appliances and consumer devices.”

The new smart electric grid paradigm creates a complex environment that requires decision making, developing and deploying advanced technologies, and facilitating the exchange of energy and information between interested parties. One of the ways that users (customers) could interact with a smart electric grid is through demand response (DR), a process by which electric power consumption (demand) is moderated to support grid needs. DR is commonly used to reduce peaks, but can also be used to increase consumption when the total demand on the grid is low, to support voltage regulation, or for other grid needs. DR can be implemented using dynamic prices or other signals from the grid. Some methods for implementing DR and the possible benefits are described in [5].

Realizing a smart electric grid requires intelligent control algorithms to facilitate autonomous interaction between homeowners and the grid. Many optimization models and control algorithms for DR have been proposed in the literature to achieve this goal. Comprehensive reviews of utility DR programs, approaches, and optimization techniques are presented in [6][8]. Common optimization objectives include cutting cost, reducing energy consumption, or both, while trying to maintain thermal comfort. The actions resulting from the optimization include controlling appliances, performing temperature setbacks, and preheating or precooling. However, it has been hard to compare these approaches because they make different assumptions and consider different objectives. Furthermore, they may consider the perspective of the utility (cost, profit, peak load shaving, capacity, etc.), but fail to consider that the perspective of the homeowner whose needs or interests (energy, cost, comfort, etc.) may be different. A user may also have conflicting goals such as reducing cost and maintaining comfort. Therefore, an assessment framework is needed that can evaluate the impact of control 
actions on multiple and potentially conflicting objectives such as minimizing cost or energy while maintaining thermal comfort or other user preferences. Considering those objectives, the framework must also enable a direct comparison of the performance of residential energy management control algorithms (EMCA).

There is an extensive literature describing approaches for comparing residential EMCAs. A unifying theme throughout the literature is centered on comparing the performance of proposed residential EMCAs on energy cost savings [9]-[14], energy savings [11], [13], [15], [16], peak load reduction [9], [10], [13], [17], and thermal comfort [11], [13], [15] to an established baseline. In [18] the authors proposed a data-driven framework for comparing the energy performance of residential thermostats controlling central heating, ventilating, and air-conditioning (HVAC) systems. Using thermostat field data, the proposed framework applied different assessment techniques to separately consider behavioral attributes (setpointrelated) from non-behavioral attributes such as HVAC control strategies and fault detection and diagnostics (FDD). Setpoint-related energy impacts were evaluated from a data-driven method using a building simulation model, while HVAC and FDD control impacts were determined using traditional testing methods such as field experiments. The results were integrated to determine typical energy performance of residential thermostats relative to a specified baseline. The baseline was a fixed seasonal temperature that a typical homeowner would prefer to maintain if setbacks were not available. Using historical data, a user's preferred baseline was determined from seasonal hourly setpoints by calculating the $90^{\text {th }}$ percentile value for heating season and $10^{\text {th }}$ percentile value for the cooling season.

However, little has been reported on a comprehensive framework for assessing the performance of residential EMCAs considering multiple objectives and users' subjective preferences simultaneously. Developing a comprehensive framework requires the use of a multi-criteria decision-making mechanism that can handle both subjective preferences from users and objective analyses from performance data generated because of using residential EMCAs. A few examples of using such a hybrid mechanism (subjective and objective analyses) have been given in the literature. The authors in [19], [20] presented an assessment framework based on the Analytical Hierarchy Process (AHP) that combines subjective analyses from expert judgments with objective data derived from analytical methods to rank alternatives. The assessment framework in [19] was used to choose the best sustainable building envelope design among alternatives, while in [20] a case study was presented for choosing the best HVAC system design for a building. The decision was informed by incorporating uncertainty analysis into selecting building design parameters.

Although the frameworks presented in [19], [20], in concept, are similar to the work described in this study, the domain of the problems are fundamentally different. The objective of [19], [20] was to make design decisions, but the main objective of this study is to develop an assessment framework capable of comparing and ranking different residential EMCAs. Assessing the performance of residential EMCAs is a multi-criteria decision making problem 
because multiple and conflicting objectives (such as minimizing cost while maintaining comfort or other user preferences) apply simultaneously.

Unlike prior studies, the proposed framework will:

1. Provide a systematic mechanism for comparing the overall performance of residential EMCAs in terms of energy consumption, cost, and comfort while actively allowing users to interact with the framework to capture the impact of their preferences on the ranking and decision making;

2. Provide an algorithm for mapping quantitative performance data to the comparison scale of the AHP and consequently creating a matrix of pairwise comparison (MPC), and

3. Calculate all relative weights (priorities) for both subjective (user's preferences) and objective performance data using the methodology described in the AHP framework.

To implement the proposed framework, an assessment engine (AE) was developed as shown schematically in Figure 1. The AE incorporates subjective and objective analyses, deriving priorities from user's input and performance data resulting from different residential EMCAs. It performs the evaluation and ranking of residential EMCAs using AHP. A case study of the proposed AE, applied to six residential EMCAs, is presented.

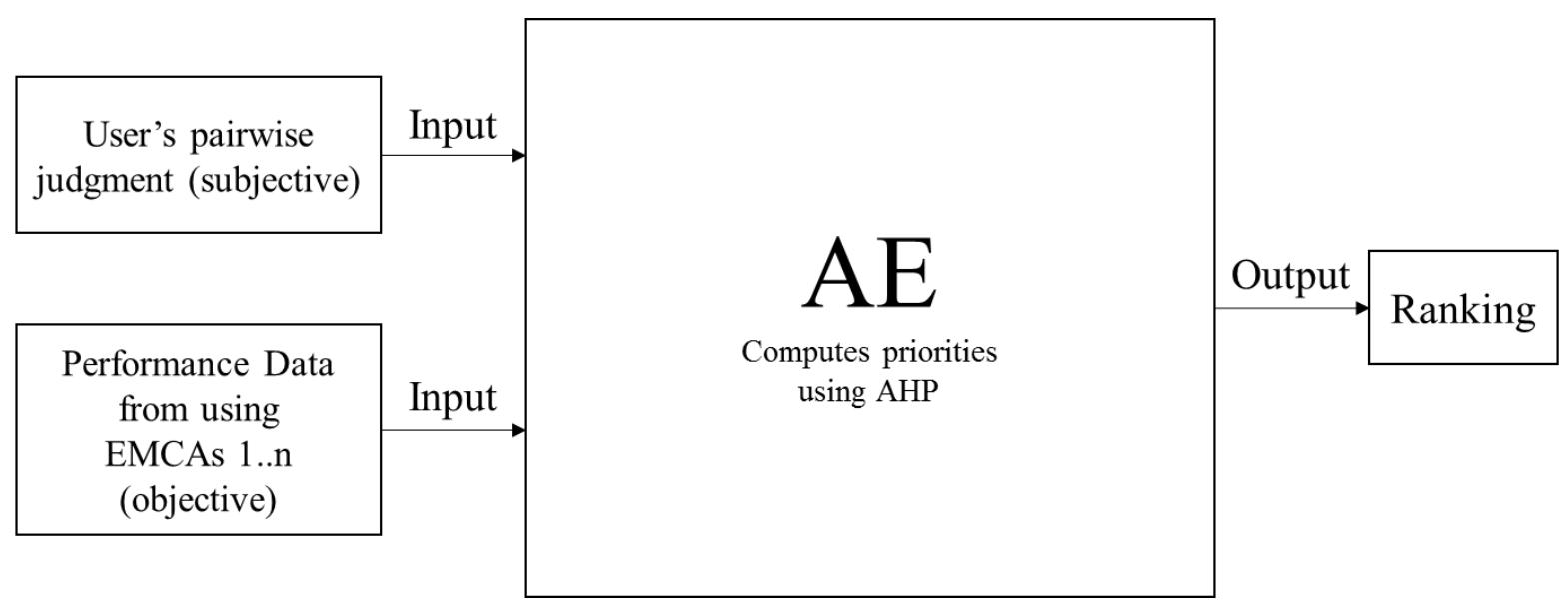

Figure 1. A schematic representation of the assessment process

\section{Analytical Hierarchy Process}

AHP is a multi-criteria decision-making (MCDM) method developed by Saaty [21]. It has been commonly used in solving decision-making problems that consider both quantitative and qualitative analysis [19], [20], [22], [23]. A comprehensive review of the application of AHP to planning, choosing among alternatives, allocating resource, etc., is presented in [24]. The American Society for Testing and Materials (ASTM) Standard E1765 documents a procedure for applying AHP to investments related to buildings and building systems [25]. The main principles of the AHP are hierarchy, pairwise comparison, and principle eigenvector. AHP decomposes a MCDM problem into a hierarchy to handle its numerous or multi-faceted criteria and to keep the number of pairwise comparisons manageable [23]. The goal (objective) of the 
problem is placed at the top of the hierarchy. The alternatives are positioned at the bottom of the hierarchy, while the criteria and sub-criteria occupy the intermediate levels. To illustrate this, consider a hypothetical example of a couple that is purchasing a house. The couple decided to use the AHP and follow its prescribed steps to achieve their goal. At the first step, they have determined their goal. The goal is to find the house that best suits their needs. At the second step, they have identified the three most important criteria (building size, location, and price) for selecting their desired home. At the third step, they identified three existing homes (alternatives) labeled as H1, H2, and $\mathrm{H} 3$. Figure 2 shows the decomposition of this hypothetical problem into a hierarchical arrangement. Each line shows a relationship between an alternative and the criterion above it, or the relationship between the criterion and the goal. These relationships are mathematically represented by priorities, for example, $P_{H 1 \text {,Size }}$ is the priority of the alternative $H 1$ with respect to the criterion Size and $P_{\text {Size,Goal }}$ represents the priority of the criterion Size to the Goal.

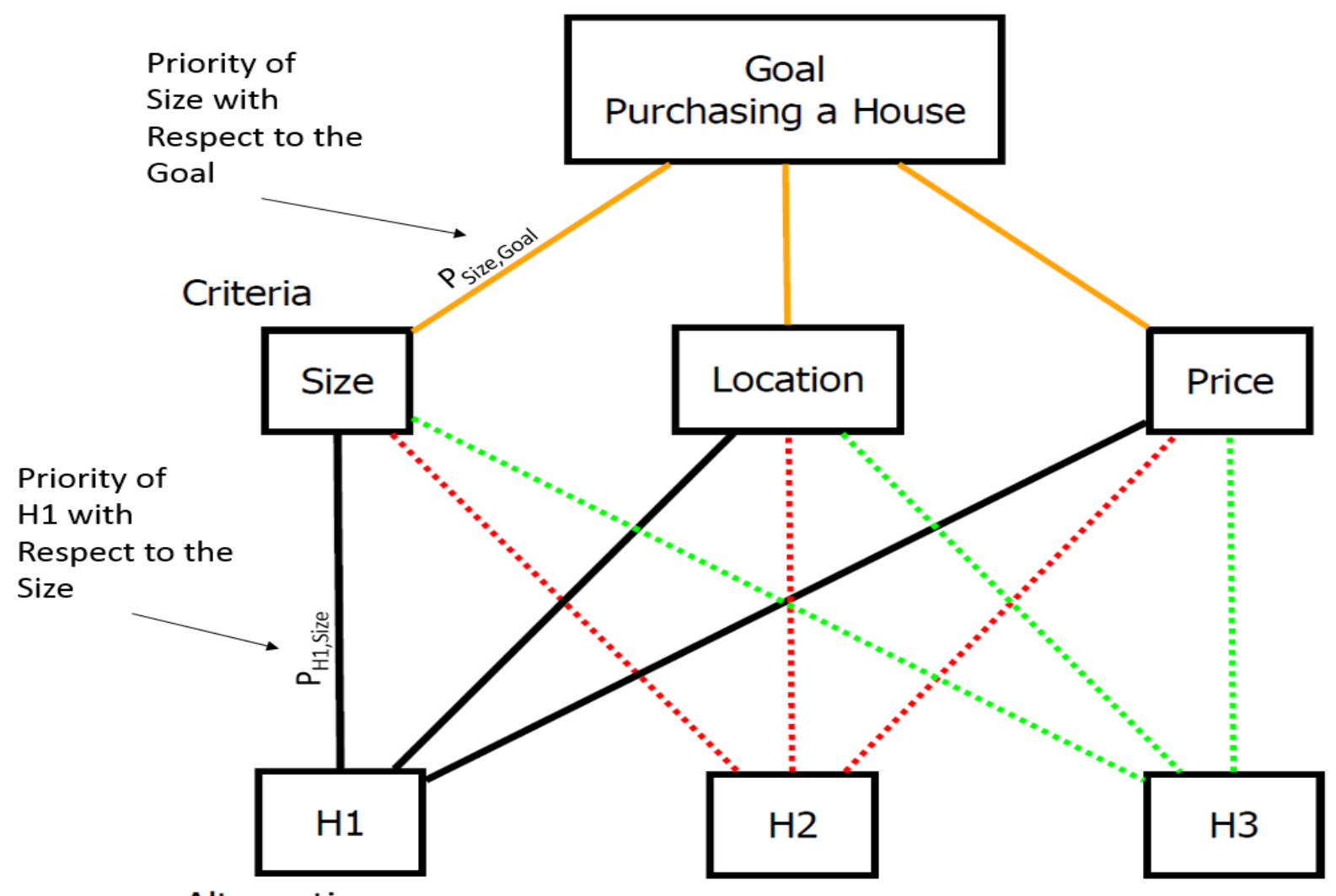

\section{Alternatives}

Figure 2. Decomposition of the hypothetical problem of purchasing a house into a hierarchy

At the fourth step, the couple needs to build an MPC (decision matrix) for comparing criteria to each other with respect to the goal of purchasing a house. Each element of an MPC is created by comparing one criterion with another criterion i.e., Size (activity $i$ ) is compared with Location (activity $j$ ). To create an MPC, the couple must first judge which criterion is more desirable with respect to reaching their goal. After much discussion, the couple expresses their subjective judgments (expert knowledge) as follows: 
1. Location of the house is strongly preferred over the size of the house because of a desire to be near schools and shopping centers;

2. Price of the house is slightly preferred over the size of the house because the budget is fixed; and

3. Location of the house is slightly preferred over the price of the house because of a desire to be near schools and shopping centers.

AHP enables the couple (decision makers) to translate their preferences (subjective judgments) into precise numbers using a 1-9 numerical scale shown in Table 1.

Table 1. The AHP Fundamental Scale, Adapted from Table 3-1 p. 54 of [21]

\begin{tabular}{|c|l|l|}
\hline \multicolumn{3}{|c|}{ The Fundamental Scale for Pairwise Comparisons } \\
\hline $\begin{array}{c}\text { Intensity of } \\
\text { Importance }\end{array}$ & \multicolumn{1}{|c|}{ Definition } & \multicolumn{1}{c|}{ Explanation } \\
\hline 1 & Equal importance & $\begin{array}{l}\text { Two activities contribute equally to the } \\
\text { objective }\end{array}$ \\
\hline 3 & $\begin{array}{l}\text { Weak importance of } \\
\text { one over another }\end{array}$ & $\begin{array}{l}\text { Experience and judgment slightly favor } \\
\text { one activity over another }\end{array}$ \\
\hline 5 & $\begin{array}{l}\text { Essential or strong } \\
\text { importance }\end{array}$ & $\begin{array}{l}\text { Experience and judgment strongly favor } \\
\text { one activity over another }\end{array}$ \\
\hline 7 & $\begin{array}{l}\text { Very strong or } \\
\text { demonstrated } \\
\text { importance }\end{array}$ & $\begin{array}{l}\text { An activity is favored very strongly over } \\
\text { another; its dominance demonstrated in } \\
\text { practice }\end{array}$ \\
\hline 9 & $\begin{array}{l}\text { Absolute importance } \\
\text { The evidence favoring one activity over } \\
\text { another is of the highest possible order of } \\
\text { affirmation }\end{array}$ \\
\hline $2,4,6,8$ & $\begin{array}{l}\text { Intermediate values } \\
\text { between adjacent scale } \\
\text { values }\end{array}$ & \begin{tabular}{l} 
When compromise is needed \\
\hline
\end{tabular} \\
\hline
\end{tabular}

Using AHP's fundamental scale, the couple translated their subjective preferences into numeric values as shown in Table 2. For example, since the location of the house is strongly preferred over its size, the table entry for the intersection of the Location row and Size column is assigned the value 5, indicating that location is five times more important than size. The inverse value, 1/5, is assigned to the table entry for the intersection of the Size row and Location column. The couple translates all preferences to numerical values in a similar manner.

Table 2. Criteria compared with respect the Goal for purchasing a house

\begin{tabular}{|c|c|c|c|}
\hline & Size & Location & Price \\
\hline Size & 1 & $1 / 5$ & $1 / 3$ \\
\hline Location & 5 & 1 & 3 \\
\hline Price & 3 & $1 / 3$ & 1 \\
\hline
\end{tabular}


At the fifth step, the couple needs to build an MPC for comparing alternatives to each other with respect to each criterion. Each element of an MPC is created by comparing one alternative with another alternative i.e., H1 (activity $i$ ) is compared with H2 (activity $j$ ). To create an MPC, the couple must first judge which alternative is more desirable with respect to the criterion that is being considered i.e., Size. After much discussion, the couple expresses their subjective judgments as follows:

1. $\mathrm{H} 1$ is very strongly preferred over $\mathrm{H} 2$ because it meets the space requirement of our family;

2. Although $\mathrm{H} 1$ and $\mathrm{H} 3$ meets the space requirement, the bathroom in $\mathrm{H} 3$ is somewhat smaller so $\mathrm{H} 1$ is strongly preferred over $\mathrm{H} 3$; and

3. H3 is slightly preferred over H2 because the kitchen is somewhat bigger.

Using the procedure highlighted in the step four, the couple forms the following MPC for comparing alternatives with respect to the criterion Size:

Table 3. Alternatives compared with respect the criterion Size

\begin{tabular}{|c|c|c|c|}
\hline & H1 & H2 & H3 \\
\hline H1 & 1 & 7 & 5 \\
\hline H2 & $1 / 7$ & 1 & $1 / 3$ \\
\hline H3 & $1 / 5$ & 3 & 1 \\
\hline
\end{tabular}

The MPCs for comparing alternatives with respect to Location and Price criteria are obtained in a similar manner. In general, the result of pairwise comparisons between activity $i$ and activity $j$ are stored in an MPC (n-by-n matrix) of the form

$$
A=\left[\begin{array}{cccc}
1 & a_{12} & \cdots & a_{1 n} \\
1 / a_{12} & 1 & \cdots & a_{2 n} \\
\vdots & \vdots & :: \vdots & \vdots \\
1 / a_{1 n} & 1 / a_{2 n} & \cdots & 1
\end{array}\right],
$$

where $a_{i j}$ is the numerical representation of the quantified judgments on pairs (activity $i$, activity $j$ ) for all activities $(i, j=1,2, \ldots, \mathrm{n})$ [21] where $i$ denotes a row and $j$ denotes a column entry of the matrix A. The diagonal of the matrix $\mathrm{A}$ is equal to one because activity $i$ is always as important as itself. The activities below the diagonal are the reciprocal values of the corresponding activities above the diagonal because if activity $i$ is four times as important as activity $j$, then activity $j$ is one fourth as important as activity $i$. More explicitly, the following rules adapted from [21] define the $a_{i j}$ entries:

Rule 1. If $a_{i j}=\sigma$ then $a_{j i}=1 / \sigma, \sigma \neq 0$; and

Rule 2. If activity $i$ is judged to be of equal relative importance as activity $j$, then $a_{i j}=1, a_{j i}=1$, and $a_{i i}=1$ for all $i$. 
Once the judgments are recorded in the matrix A, AHP uses the principle eigenvector method to derive priorities or weights (normalized to sum to one) for the criteria and alternatives. It also uses the principle eigenvalue, $\lambda_{\max }$, to check for consistency between pairwise comparisons. The eigenvalue/eigenvector in matrix notation is given by

$$
A w=\lambda_{\max } w,
$$

where:

$A$ is the reciprocal matrix with entries $a_{i j}$ for all $(i, j=1,2, \ldots, n)$;

$w$ is the eigenvector; and

$\lambda_{\max }$ is the principle eigenvalue.

If the judgments in the matrix A are perfectly consistent, then the value of $\lambda_{\max }$ is equal to $\mathrm{n}$ (number of activities). In AHP, the deviation from consistency is a violation of proportionality [21] and shows an inherent possibility of bias and errors in the judgements [23]. Two metrics are recommended in [21] as measure of the consistency of pairwise comparisons, the consistency index (CI) and consistency ratio (CR). CI is the difference between the principle eigenvalue and $n$, and is mathematically defined as $\left(\lambda_{\max }-n\right) /(n-1)$. CR is a measure of the goodness of $C I$ and it is defined as $C I / R I$. The random index $R I$, is an average $C I$ of randomly generated reciprocal matrices [21] as shown in Table 4. A CR of $10 \%$ or less is desirable, indicating good judgments when activities are pairwise compared.

Table 4. The Average RI for Matrices of Order 1-15, Adopted from p. 21of [21]

\begin{tabular}{|c|c|c|c|c|c|c|c|c|c|c|c|c|c|c|c|}
\hline $\begin{array}{c}\text { Matrix } \\
\text { Order }\end{array}$ & 1 & 2 & 3 & 4 & 5 & 6 & 7 & 8 & 9 & 10 & 11 & 12 & 13 & 14 & 15 \\
\hline $\begin{array}{c}\text { Average } \\
\text { RI }\end{array}$ & 0.00 & 0.00 & 0.58 & 0.90 & 1.12 & 1.24 & 1.32 & 1.41 & 1.45 & 1.49 & 1.51 & 1.48 & 1.56 & 1.57 & 1.59 \\
\hline
\end{tabular}

The final step in AHP is to calculate the overall score for each alternative with respect to the goal. Consider the hierarchical arrangement of the hypothetical problem of purchasing a house with three levels: the goal, criteria, and alternatives. Let $w g$ represent the vector of priorities derived for each criterion with respect to the goal (that is, the principal eigenvector of the MPC for the goals), and $m$ be the number of criteria. Let $p_{a}$ represent the vector of priorities derived for an alternative with respect to criteria in the level above it (that is, the principal eigenvector of the MPC for each of the criteria). The overall score for alternative $a\left(S_{a}\right)$ with respect to the goal is computed by

$$
S_{a}=\sum_{k=1}^{m} p_{a}(k) w g(k) .
$$

Using Eq. (1.2), the overall scores for all alternatives are computed. The sum of priorities at each level of the hierarchy must equal one. The alternative with the highest score is the most desirable one. Applying these definitions to the hypothetical problem of purchasing a house, give us the following results:

$$
\begin{aligned}
& w g=[0.11,0.63,0.26] \\
& p_{\text {size }}=[0.73,0.08,0.19],
\end{aligned}
$$

where: 
$w g$ is the vector of priorities derived for each criterion with respect to the Goal and is computed from the MPC shown in Table 2; and

$p_{\text {size }}$ is the vector of priorities derived for each alternative with respect to the criterion Size from the MPC shown in Table 3.

The vector of priorities for each alternative with respect to the criteria Location and Price are obtained in a similar manner as $p_{\text {size. }}$ These priorities are given below:

$$
\begin{aligned}
p_{\text {location }} & =[0.16,0.59,0.25] \\
p_{\text {price }} & =[0.25,0.50,0.25],
\end{aligned}
$$

where:

$p_{\text {location }}$ is the vector of priorities derived for each alternative with respect to the criterion Location; and

$p_{\text {price }}$ is the vector of priorities derived for each alternative with respect to the criterion Price.

Therefore, the vector of priorities for each alternative with respect to the criteria is given by

$$
\begin{aligned}
& p_{\mathrm{H} 1}=[0.73,0.16,0.25] \\
& p_{\mathrm{H} 2}=[0.08,0.59,0.50] \\
& p_{\mathrm{H} 3}=[0.19,0.25,0.25] .
\end{aligned}
$$

The relationship between alternative houses, criteria, and the goal of purchasing a house are shown in Figure 3. 


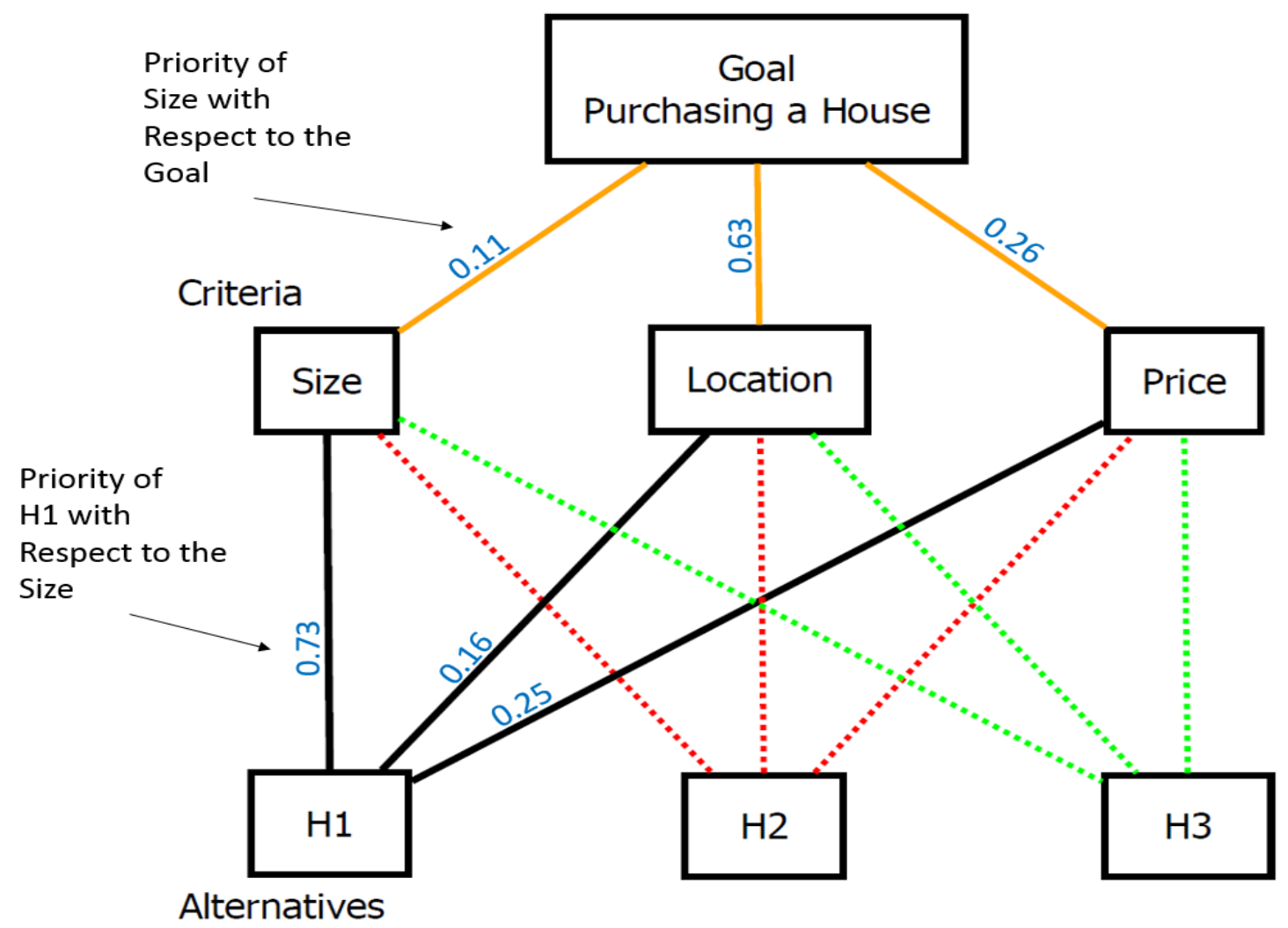

Figure 3. Summary figure showing the relationship between alternatives, criteria, and the goal using priorities for one alternative

Applying Eq. (1.2) to the derived priorities, the overall scores for each alternative with respect to the Goal is given in Table 5. For example, the overall score for $\mathrm{H} 1$ is computed by

$$
\begin{aligned}
S_{\mathrm{H} 1} & =\sum_{k=1}^{3} p_{\mathrm{H} 1}(k) w g(k) \\
& =0.25 .
\end{aligned}
$$

Table 5. The overall scores of alternatives for purchasing a house

\begin{tabular}{|c|c|}
\hline Alternatives & Overall Score $\mathbf{( S}_{\mathbf{a}} \mathbf{)}$ \\
\hline H1 & 0.25 \\
\hline H2 & 0.51 \\
\hline H3 & 0.24 \\
\hline
\end{tabular}

Based on the overall scores in Table 5, the most desirable outcome for the couple is to purchase the second house (H2). 


\section{Problem Hierarchy Assessing EMCAs}

The proposed AE splits the problem of assessing the performance of residential EMCAs into a three-level hierarchy: the goal, criteria, and alternatives as shown in Figure 4.

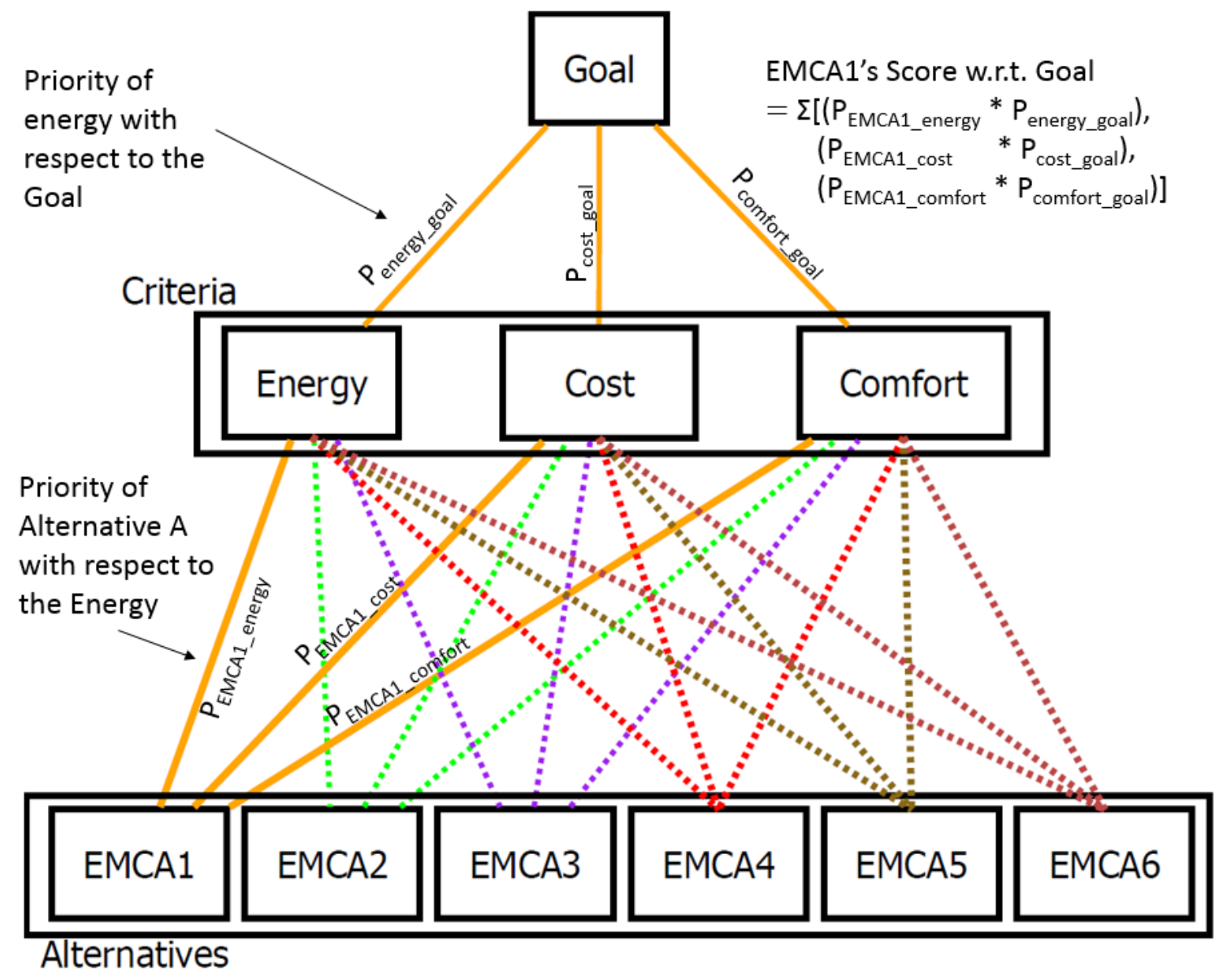

Figure 4. The assessment problem hierarchy showing the relationship of the alternatives to the criteria and the goal

The goal is to identify the best alternative given the user's preferences and the performance data resulting from the use of residential EMCAs. Energy, cost, and comfort were selected as the criteria because they can be controlled by a residential EMCA and have a significant impact on the overall well-being of the occupants and because they can help utilities with peak demand reduction. In this study YALMIP [26], a MATLAB toolbox, was used to implement six residential EMCAs that controlled a two-stage heat pump with auxiliary electric heating.

The main objective of developing these residential EMCAs was to create a diverse set of realistic operating scenarios for the $\mathrm{AE}$ to evaluate and rank. A detailed description and mathematical derivation of these algorithms is provided in [27]. A summary of important parameters for residential EMCAs used in this study is presented in Table 6. The $(\checkmark$,Yes) and $(\boldsymbol{x}, \mathrm{No})$ markers are used to indicate whether an algorithm is single-objective or multi-objective or limited by the upper or lower bound indoor temperature constraints. For example, residential 
EMCA3 used optimization $(\checkmark)$, was not limited by upper and lower bound constraints $(\boldsymbol{x})$, and was multi-objective $(\checkmark)$.

\section{Table 6. Summary Description of Residential EMCAs}

\begin{tabular}{|c|c|c|c|c|c|c|c|c|c|c|}
\hline 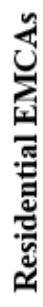 & 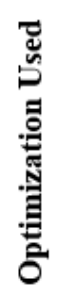 & 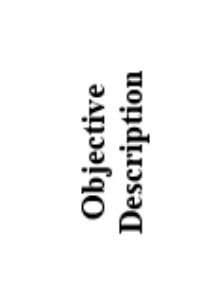 & 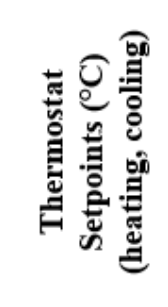 & \multicolumn{2}{|c|}{ 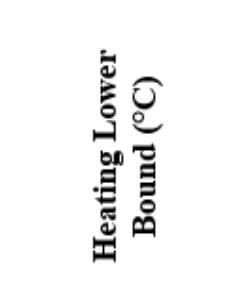 } & \multicolumn{2}{|c|}{ 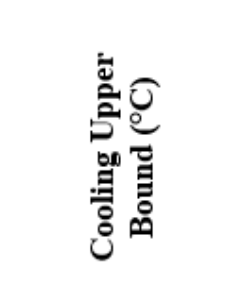 } & 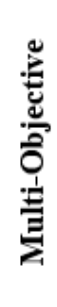 & 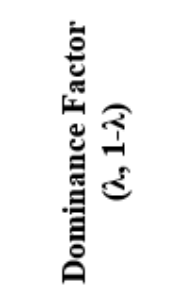 & 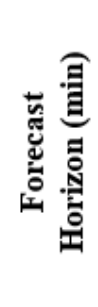 \\
\hline 1 & $\checkmark$ & $\begin{array}{c}\text { Minimize } \\
\text { Energy }\end{array}$ & $(20.5,23.9)$ & \multicolumn{2}{|c|}{20.2} & \multicolumn{2}{|c|}{24.2} & $x$ & $x$ & 30 \\
\hline 2 & $\checkmark$ & Minimize Cost & $(20.5,23.9)$ & \multicolumn{2}{|c|}{20.2} & \multicolumn{2}{|c|}{24.2} & $x$ & $x$ & 1440 \\
\hline 3 & $\checkmark$ & $\begin{array}{c}\text { Minimize } \\
\text { Discomfort }+ \\
\text { Cost }\end{array}$ & $(20.5,23.9)$ & \multicolumn{2}{|l|}{$x$} & \multicolumn{2}{|l|}{$x$} & $\checkmark$ & $(0.45,0.55)$ & 240 \\
\hline 4 & $\checkmark$ & $\begin{array}{c}\text { Minimize } \\
\text { Discomfort }+ \\
\text { Cost }\end{array}$ & $(20.5,23.9)$ & \multicolumn{2}{|l|}{$x$} & \multicolumn{2}{|l|}{$x$} & $\checkmark$ & $(0.55,0.45)$ & 240 \\
\hline \multirow{3}{*}{5} & \multirow{3}{*}{$x$} & \multirow{3}{*}{ NZERTF Case } & \multirow{3}{*}{$(20.5,23.9)$} & $1^{\text {st }}$ Stage & 20.4 & $1^{\text {st }}$ Stage & 24.1 & \multirow{3}{*}{$x$} & \multirow{3}{*}{$x$} & \multirow{3}{*}{$x$} \\
\hline & & & & $2^{\text {nd }}$ Stage & 19.4 & $2^{\text {nd }}$ Stage & 27.1 & & & \\
\hline & & & & $3^{\text {rd }}$ Stage & 17.2 & $x$ & $x$ & & & \\
\hline \multirow{3}{*}{6} & \multirow{3}{*}{$x$} & \multirow{3}{*}{$\begin{array}{l}\text { NZERTF Case } \\
\text { with Relaxed } \\
\text { Deadbands }\end{array}$} & \multirow{3}{*}{$(20.5,23.9)$} & $1^{\text {st }}$ Stage & 20.0 & $1^{\text {st }}$ Stage & 24.5 & \multirow{3}{*}{$x$} & \multirow{3}{*}{$x$} & \multirow{3}{*}{$x$} \\
\hline & & & & $2^{\text {nd }}$ Stage & 19.0 & $2^{\text {nd }}$ Stage & 27.1 & & & \\
\hline & & & & $3^{\text {rd }}$ Stage & 16.8 & $x$ & $x$ & & & \\
\hline
\end{tabular}

The first four residential EMCAs in Table 6 utilize an integer linear programming solver (intlinprog) in MATLAB to forecast control actions for operating the heat pump unit. The forecast horizon time is shown in Table 6.

Residential EMCA1 and residential EMCA2 are formulated as single-objective optimization problems. They both have the same upper and lower bound indoor temperature constraints, but different optimization horizons. In the heating season, the residential EMCAs are constrained to forecast the indoor temperature such that it remains between the heating setpoint and its lower bound limit. In the cooling season, the residential EMCAs are constrained to forecast the indoor temperature such that it remains between the cooling setpoint and its upper bound limit. The forecast horizon for the two algorithms are different because residential EMCA2 is trying to minimize the operating cost of using the heat pump by taking advantage of a real-time pricing (RTP) structure.

Residential EMCA3 and residential EMCA4 are formulated as multi-objective optimization problems with two competing terms, one is trying to maintain the thermal comfort of the occupants while the other one is trying to minimize the energy cost. The comfort term is the absolute value of the difference between the forecasted indoor temperature and the thermostat setpoint (for both heating and cooling seasons). The cost term is the sum of the product of the heat pump energy and the price of electricity during each hour. Both algorithms have the same structure, but they emphasize different terms of the objective function as reflected by the 
Dominance Factor. Residential EMCA3 emphasizes cost savings while residential EMCA4 emphasizes comfort.

Residential EMCA5 was designed to replicate the heat pump controller used in the Net-Zero Energy Residential Test Facility (NZERTF) and the simulation results were validated with experimentally measured performance [28]. In the heating season, residential EMCA5 uses the heating lower bound temperatures, as given in Table 6, to manage the operation of the heat pump. The $1^{\text {st }}$ Stage of the heat pump is activated when the indoor temperature falls below the $1^{\text {st }}$ Stage lower bound temperature. The $2^{\text {nd }}$ Stage of the heat pump is activated when the indoor temperature either falls below the $2^{\text {nd }}$ Stage lower bound or the heat pump has operated in the $1^{\text {st }}$ Stage for more than 10 minutes. The $3^{\text {rd }}$ Stage electric heating is activated when the indoor temperature either falls below the $3^{\text {rd }}$ Stage lower bound temperature or the heat pump has operated in $2^{\text {nd }}$ Stage for more than 40 minutes. In the cooling season, the $1^{\text {st }}$ Stage of the heat pump is activated when the indoor temperature rises above the $1^{\text {st }}$ Stage upper bound temperature. The $2^{\text {nd }}$ Stage is turned on when either the indoor temperature has risen above the $2^{\text {nd }}$ Stage upper bound or the heat pump has operated in the $1^{\text {st }}$ Stage for more than 40 minutes. Residential EMCA6 uses the same control logic to operate the heat pump, but its upper and lower bounds are relaxed.

The residential EMCAs were linked to a TRNSYS simulation model [28] of the NZERTF at NIST in Gaithersburg, Maryland [29]. Measured data from the NZERTF were used to validate the model. NZERTF is a research house that is comparable in size and aesthetics to the upscale suburban houses currently being built in the greater Washington, DC metro area. The NZERTF serves two purposes: (1) to demonstrate the feasibility of achieving net zero energy operation (energy generated equals the total energy consumed) over the course of one year; and (2) to test existing and new energy efficiency and smart grid technologies in a low energy environment. The exterior of the NZERTF is shown in Figure 5.

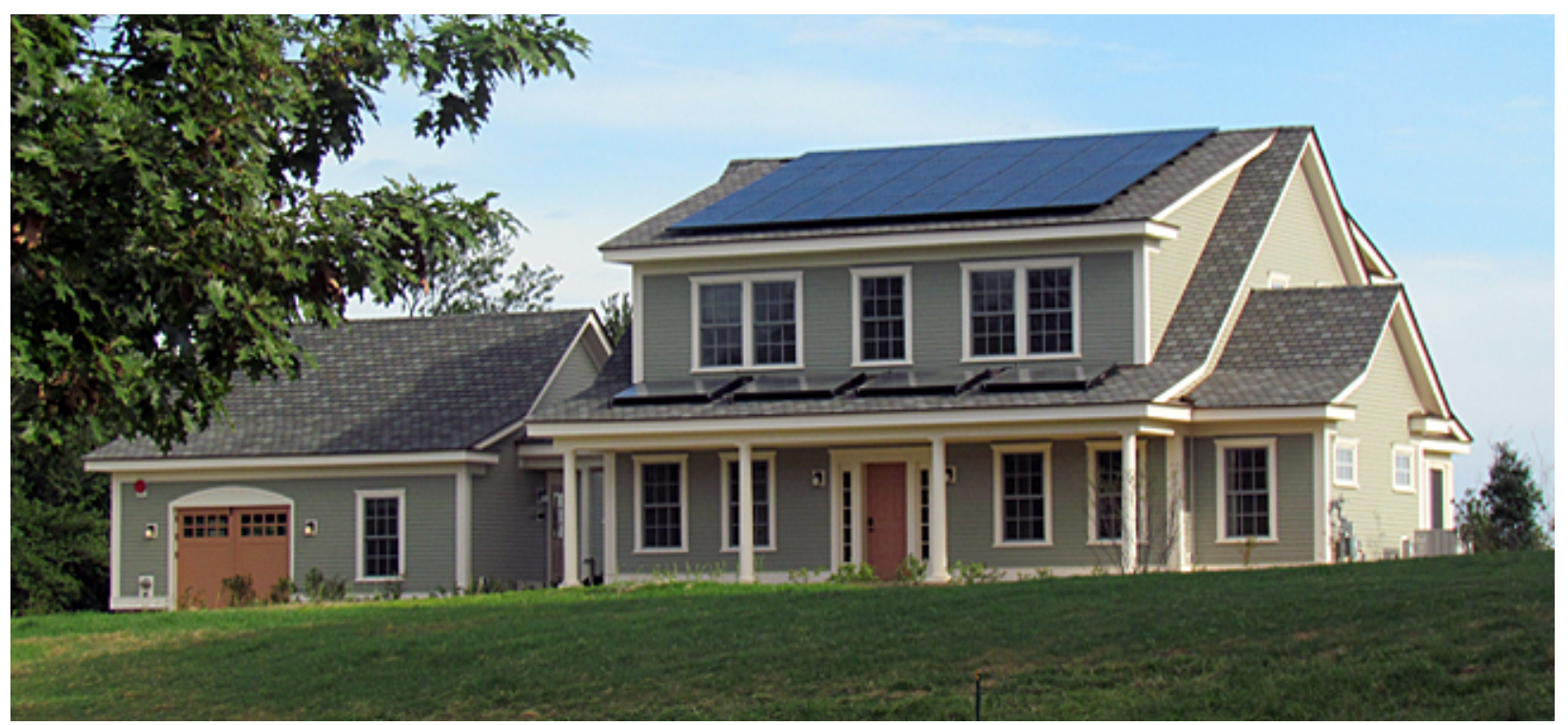

Figure 5. The exterior of the NZERTF on the campus of NIST in Gaithersburg, MD 


\section{The AE User Interface}

The AE utilizes subjective preferences (inputs from a user) and objective performance data (generated in response to the use of a residential EMCA) to perform pairwise comparisons and ultimately help users select the best alternative among all alternatives. The AE user interface (AEUI), shown in Figure 6, was developed to capture user's preferences and obtain/process performance data. In its current form, users can perform the following tasks:

1. Import up to six hourly and minutely performance data files;

2. Solicit a user's preferences (expert knowledge or judgments) for pairwise comparison of energy, cost, and comfort; and

3. Perform an overall ranking of the residential EMCAs with respect to the goal.

Additionally, the AEUI provides a set of diagnostic analyses and plots comparing the residential EMCAs with respect to a base case. Any residential EMCA can be used as a base case. The diagnostic analyses can be used as a benchmarking tool, independent of the assessment and ranking.

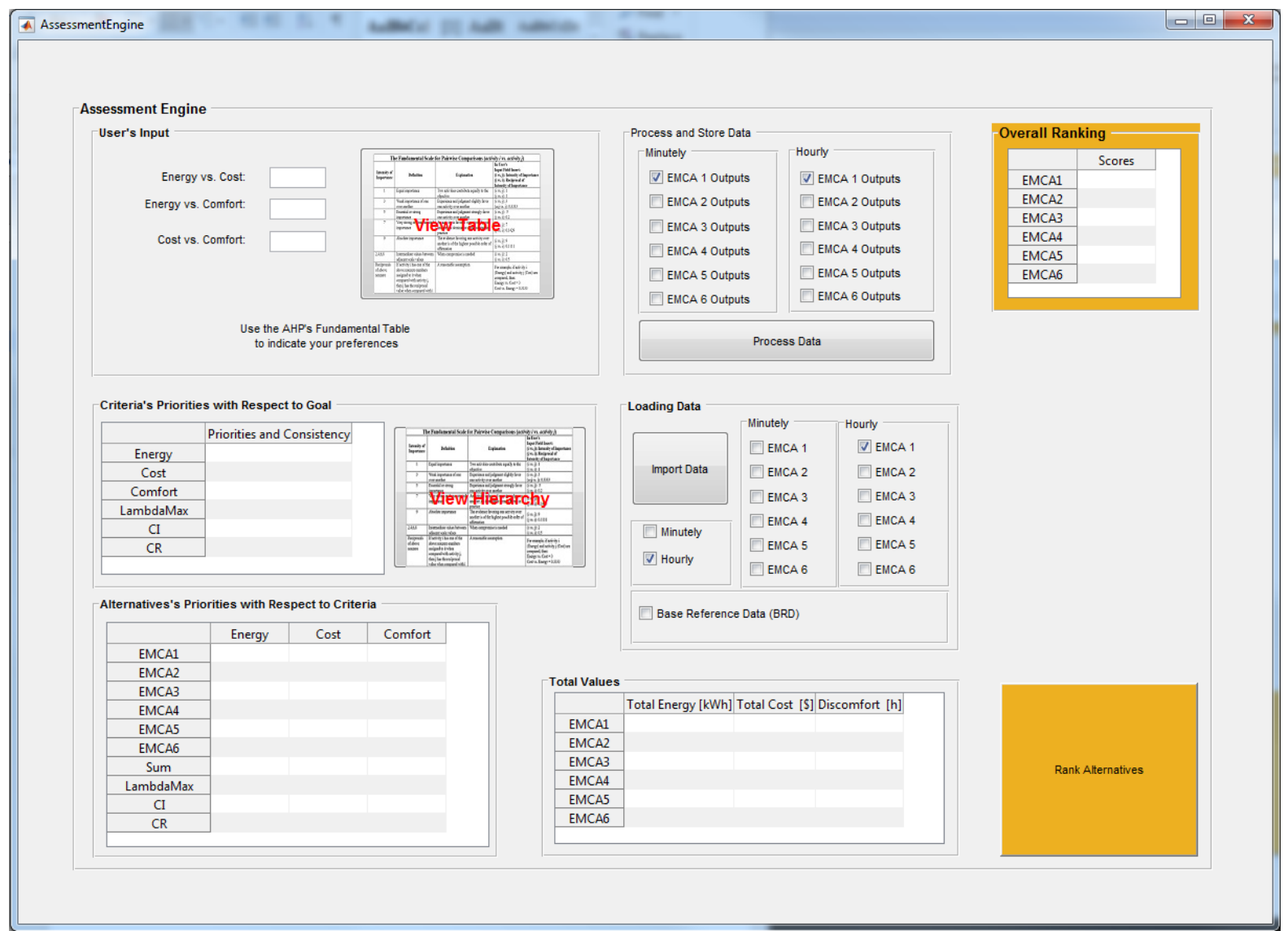

Figure 6. The AE user interface captures user's input, loads performance data, and performs ranking 


\section{Priorities from User's Judgments}

Using a user's input, the AE computes the relative priorities of the criteria with respect to the goal. A user uses the AHP's fundamental scale shown in Table 1 to express his/her desire (or expert judgment) for comparing two criteria in pairs. For example, when the cost criterion is favored very strongly over the energy criterion, the user would enter 0.1429 (1/7) in the Energy vs. Cost input field. However, if the cost criterion is slightly favored over the comfort criterion, the user would enter 3 in the Cost vs. Comfort input filed. The User's Input fields shown in Figure 7 captures these preferences.

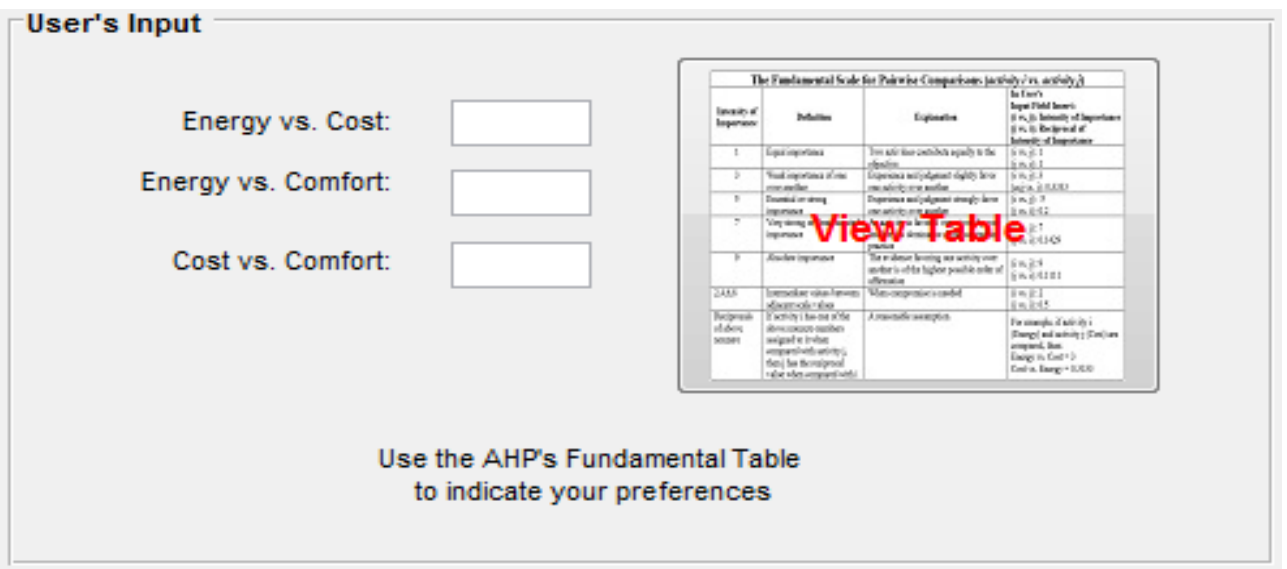

Figure 7. User's Input fields capturing preferences between criteria

Using the provided preferences, the AE forms the corresponding MPC for pairwise comparisons between selected criteria as shown in Table 7.

Table 7. MPC between Criteria

\begin{tabular}{|l|c|c|c|}
\hline & Energy & Cost & Comfort \\
\hline Energy & 1 & $1 / 7$ & $1 / 5$ \\
\hline Cost & 7 & 1 & 3 \\
\hline Comfort & 5 & $1 / 3$ & 1 \\
\hline
\end{tabular}

From this user input, the AE uses the AHP's principle eigenvector method to compute the relative priorities of each criterion with respect to the goal and the consistency of a user in judging the intensity of importance when the criteria were compared in pairs. The results from the user input shown in Table 7 are summarized in Table 8.

Table 8. Priorities and Consistency metrics

\begin{tabular}{|l|c|l|}
\hline $\begin{array}{l}\text { Criteria and consistency } \\
\text { metrics }\end{array}$ & Priorities and consistency & \\
\hline Energy & 0.07 & \multirow{2}{*}{ Priorities } \\
\hline Cost & 0.65 & \\
\hline Comfort & 0.28 & \multirow{2}{*}{ Consistency } \\
\hline$\lambda_{\max }$ & 3.07 & \\
\hline $\boldsymbol{C I}$ & 0.03 & \\
\hline $\boldsymbol{C R}$ & 0.06 & \\
\hline
\end{tabular}


For this example, cost is the most important factor for the decision maker followed by comfort and energy. Recall from Table 4 that for a matrix of order 3, the $C R$ value of $6 \%$ indicates that the decision maker was consistent in providing subjective judgments.

\section{Calculating Energy, Cost, and Comfort}

Using the performance data, the AE calculates the total energy consumption, total cost, and a discomfort index for each residential EMCA. These calculations, collectively, form the basis for computing the relative priorities of each alternative EMCA with respect to each criterion.

\subsection{Energy}

The total energy consumption is computed by

$$
E_{\text {total }, k}=\sum_{h=1}^{H} e_{h} \text { for } k=1, \ldots, n,
$$

where:

$n$ is the number of alternatives (six residential EMCAs in this case);

$H$ is the number of hours (i.e., $8760 \mathrm{~h}$ for one year); and

$e_{h}$ is the energy consumed by the HVAC unit in hour $h$ [kWh].

\subsection{Cost}

The cost of consuming energy is computed by

$$
C_{\text {total }, k}=\sum_{h=1}^{H} e_{h} \times p_{h} \text { for } k=1, \ldots, n,
$$

where:

$H, e_{h}$ and $n$ are the same as described in Eq. (1.3); and

$p_{h}$ is the RTP tariff in hour $h[\mathbb{Q} / \mathrm{kWh}]$.

The RTP tariff was derived from the day-ahead wholesale hourly price of electricity from a regional transmission organization (RTO), the Pennsylvania-New Jersey-Maryland Interconnection (PJM). The data is from January 2013 to December 2013. The day-ahead wholesale price, shown in Figure 8, was scaled to generate a forecasted retail RTP structure, resulting in an average of $15 \mathbb{\$} / \mathrm{kWh}$. The average cost of consuming energy in a residential home in Gaithersburg, Maryland is approximately $15 \mathbb{\$} / \mathrm{kWh}$ (including transmission, distribution, taxes, and fees). 


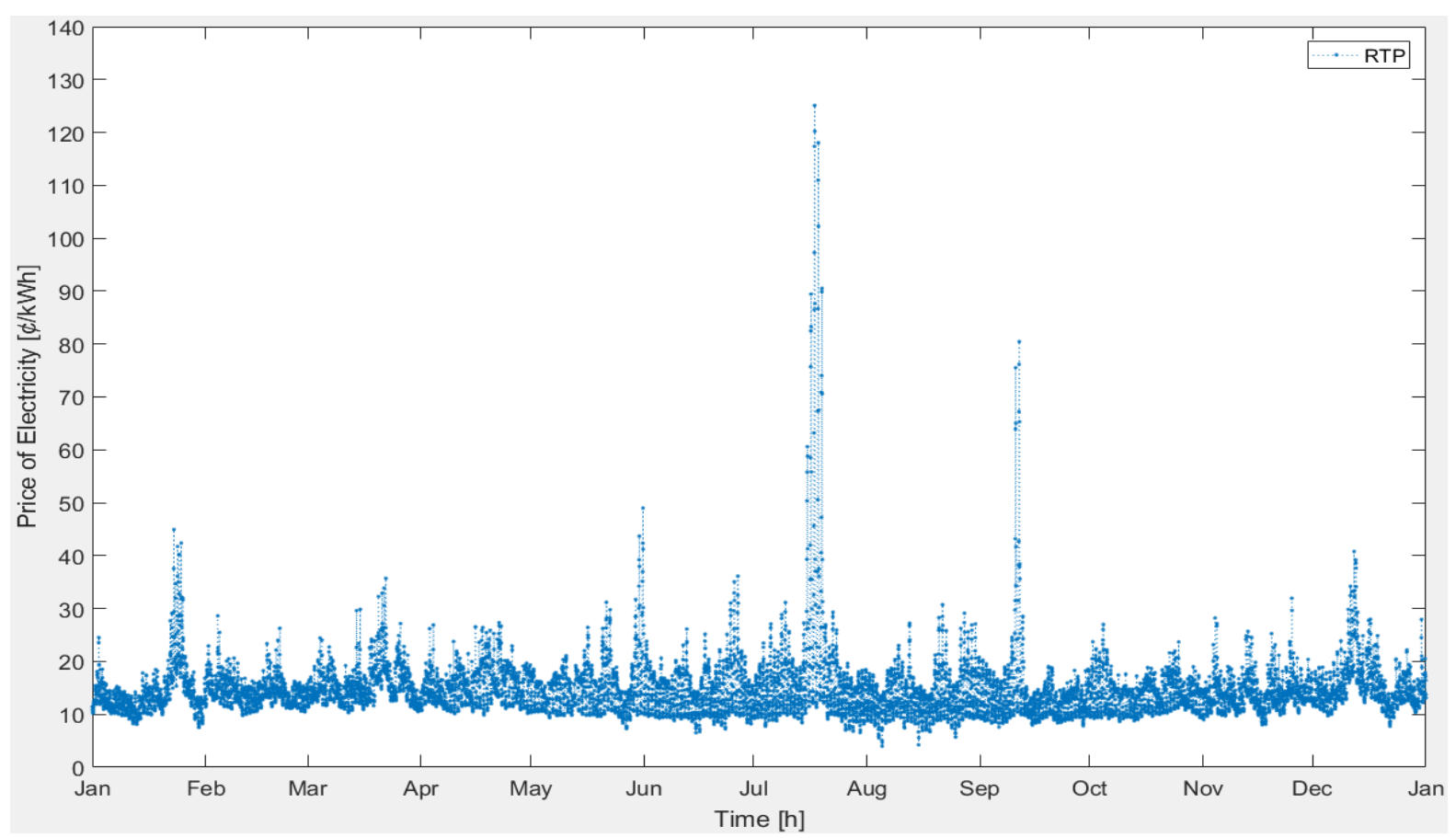

Figure 8. The hourly RTP tariff used to compute the cost of energy consumption

\subsection{Comfort}

Many long-term discomfort indices that evaluate the thermal response of humans to changes in indoor climatic conditions have been reported in the literature and standards. A review of these indices, their strengths and weaknesses are documented in [30]. In this study, a discomfort index was chosen that produced a single value, was based on well-known thermal comfort standards, and considered both the duration and severity of the thermal discomfort. The AE computes the long-term discomfort index using a methodology that is based on predicted mean vote (PMV) and predicted percentage of dissatisfied (PPD). The methodology for computing the long-term index is the PPD-weighted criterion $\left(P P D_{w c}\right)$ documented in Method C of International Organization for Standardization standard 7730 (ISO 7730) [31] and summarized in [30]. This measure of discomfort index is described as "the time during which the actual PMV exceeds the comfort boundaries is weighted with a factor that is a function of the PPD” [31].

\subsubsection{Calculating PMV and PPD}

The $P M V$ index is the mean value that predicts the response of a large group of people on the seven-point thermal sensation scale defined in [31], [32] and shown in Table 9. 
Table 9. Seven-point Thermal Sensation Scale

\begin{tabular}{|r|l|}
\hline+3 & Hot \\
\hline+2 & Warm \\
\hline+1 & Slightly warm \\
\hline 0 & Neutral \\
\hline-1 & Slightly Cool \\
\hline-2 & Cool \\
\hline-3 & Cold \\
\hline
\end{tabular}

Using heat balance principles, the $P M V$ index relates key primary thermal factors such as metabolic rate, clothing insulation, air temperature, radiant temperature, air speed, and humidity to the thermal sensation scale in Table 9. Many assumptions must be made about some of the inputs for calculating $P M V$, including that the difference between $T_{\text {air }}$ and $T_{m r t}$ is negligible. This assumption is common in previous indoor climate studies [33], [34]. Table 10 shows the input values used in this study to calculate $P M V$.

Table 10. Assumed Values for Calculating PMV

\begin{tabular}{|l|l|l|}
\hline \multicolumn{1}{|c|}{ Input data (unit) } & \multicolumn{2}{|c|}{ Assumed Value } \\
\hline Clothing (clo) & $\begin{array}{l}\text { Summer months (May, } \\
\text { June, July, August, } \\
\text { September) }\end{array}$ \\
\cline { 2 - 3 } & Other months (Walking shorts, \\
short-sleeve shirt [32])
\end{tabular}

The $P M V$ metric is calculated by using the following four equations given in ISO 7730 [31].

$$
P M V=[0.0303 \times \exp (-0.036 \times M)+0.028] \times\left\{\begin{array}{l}
(M-W)-3.05 \times 10^{-3} \\
\times\left[5733-6.99 \times(M-W)-p_{a}\right] \\
-0.42 \times[(M-W)-58.15] \\
-1.7 \times 10^{-5} \times M \times\left(5867-p_{a}\right) \\
-0.0014 \times M \times\left(34-t_{a}\right) \\
-3.96 \times 10^{-8} \times f_{c l} \times\left[\left(t_{c l}+273\right)^{4}\right. \\
\left.-\left(\overline{t_{r}}+273\right)^{4}\right]-f_{c l} \times h_{c} \times\left(t_{c l}-t_{a}\right)
\end{array}\right\}
$$




$$
\begin{gathered}
\left.t_{c l}=35.7-0.028 \times(M-W)-I_{c l} \times\left\{\begin{array}{l}
3.96 \times 10^{-8} \times f_{c l} \\
\times\left[\left(t_{c l}+237\right)^{4}-\left(\overline{t_{r}}+273\right)^{4}\right] \\
+f_{c l} \times h_{c} \times\left(t_{c l}-t_{a}\right)
\end{array}\right]\right\} \\
h_{c}= \begin{cases}2.38 \times\left|t_{c l}-t_{a}\right|^{0.25} \text { for } 2.38 \times\left|t_{c l}-t_{a}\right|^{0.25}>12.1 \times \sqrt{v_{a r}} \\
12.1 \times \sqrt{v_{a r}} & \text { for } 2.38 \times\left|t_{c l}-t_{a}\right|^{0.25}<12.1 \times \sqrt{v_{a r}}\end{cases} \\
f_{c l}=\left\{\begin{array}{ll}
1.00+1.290 l_{c l} & \text { for } l_{c l} \leq 0.078 \mathrm{~m}^{2} \times \mathrm{K} / \mathrm{W} \\
1.05+0.645 l_{c l} & \text { for } l_{c l}>0.078 \mathrm{~m}^{2} \times \mathrm{K} / \mathrm{W}
\end{array},\right.
\end{gathered}
$$

where:

$M$ is the metabolic rate in $\left(\mathrm{W} / \mathrm{m}^{2}\right), 1$ metabolic unit $=1$ met $=58.2 \mathrm{~W} / \mathrm{m}^{2}$;

$W$ is the effective mechanical power in $\left(\mathrm{W} / \mathrm{m}^{2}\right)$;

$I_{c l}$ is the clothing insulation in $\left(\mathrm{m}^{2} \mathrm{~K} / \mathrm{W}\right), 1$ clothing unit $=1 \mathrm{clo}=0.155 \mathrm{~m}^{2}{ }^{\circ} \mathrm{C} / \mathrm{W}$;

$f_{c l}$ is the clothing surface area factor;

$t_{a}$ is the air temperature in $\left({ }^{\circ} \mathrm{C}\right)$;

$\bar{t}_{r}$ is the mean radiant temperature in $\left({ }^{\circ} \mathrm{C}\right)$;

$v_{a r}$ is the relative air velocity in $(\mathrm{m} / \mathrm{s})$;

$p_{a}$ is the water vapor partial pressure in $\left(\mathrm{P}_{\mathrm{a}}\right)$;

$h_{c}$ is the convective heat transfer coefficient in $\left[\mathrm{W} /\left(\mathrm{m}^{2} \mathrm{~K}\right)\right]$; and

$t_{c l}$ is the clothing surface temperature in $\left({ }^{\circ} \mathrm{C}\right)$.

It is noted that the conversion of 1 met equals to $58.2 \mathrm{~W} / \mathrm{m}^{2}$ is based on (ANSI/ASHRAE) Standard 55 [32]. This conversion neglects body size, sex, and age of an individual, for more information regarding this conversion and topic see [36].

The $P P D$ index is determined from the $P M V$. It is a quantitative prediction of thermally dissatisfied people in percentage (\%) and it is computed by

$$
P P D=100-95 \times \exp \left(-0.03353 \times P M V^{4}-0.2179 \times P M V^{2}\right) .
$$

Computer instructions for calculating $P M V$ and $P P D$ are provided in Appendix $\mathrm{D}$ of American Nation Standards Institute /American Society of Heating, Refrigerating, and Air-Conditioning Engineers (ANSI/ASHRAE) Standard 55 [32]. The instructions were implemented in Matlab [35]. In a typical application, ANSI/ASHRAE Standard 55 also defines a recommended $P M V$ and $P P D$ range, shown in Table 11, for general thermal comfort. If the calculated values for the $P M V$ and hence for the $P P D$ are within the defined ranges, the conditions are considered to be comfortable. 
Table 11. The PMV and PPD Ranges for Thermal Comfort

\begin{tabular}{|l|l|}
\hline PMV Range & PPD (\%) \\
\hline$-0.5<$ PMV $<+0.5$ & $<10$ \\
\hline
\end{tabular}

Figure 9 shows the annual results from calculating $P M V$ and $P P D$ when residential EMCA1 is applied.
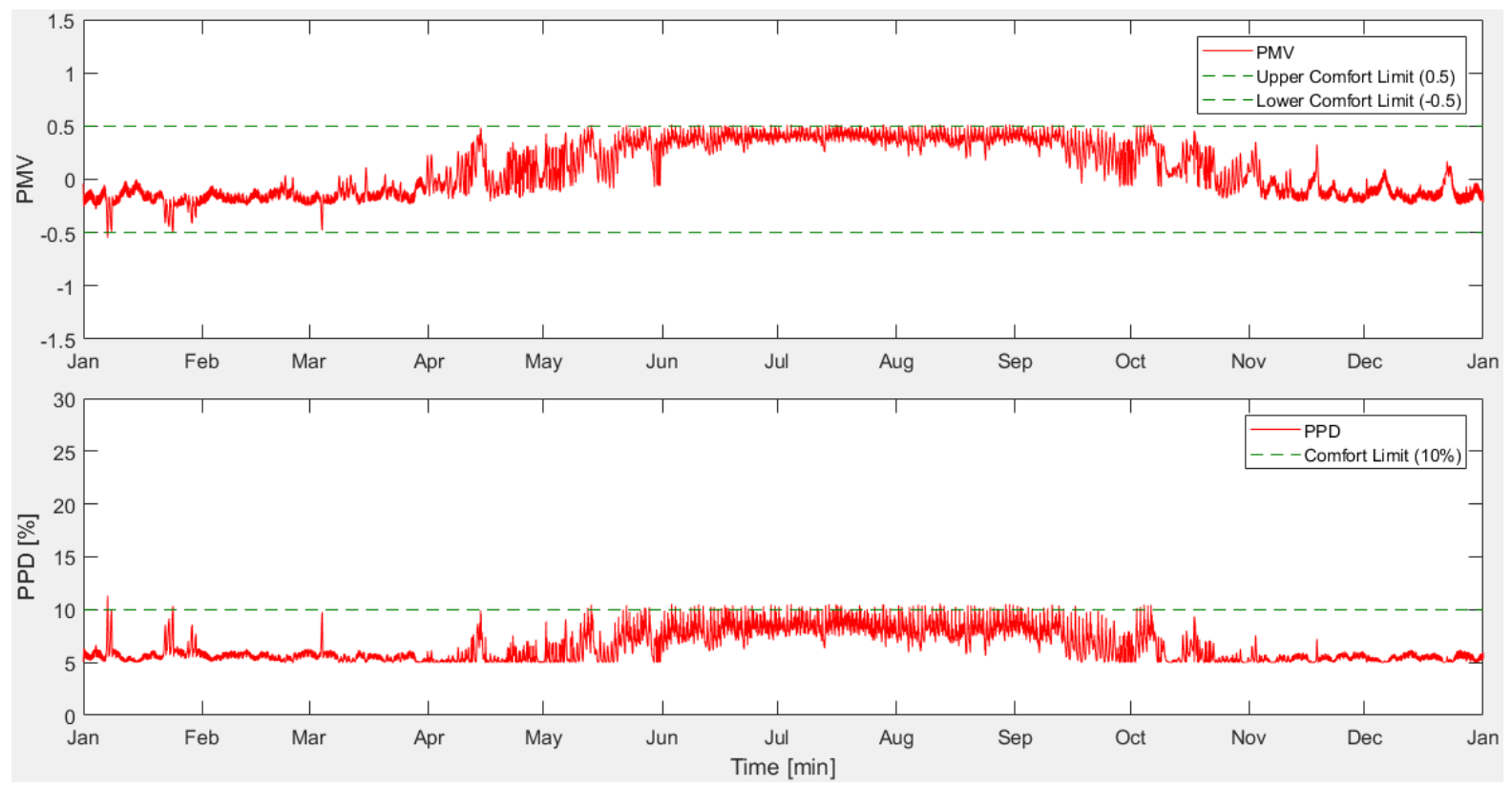

Figure 9. Annual comfort results for residential EMCA1 as measured by PMV and PPD

\subsubsection{Calculating the Discomfort Index}

The discomfort index $\left(P P D_{w c}\right)$ is the sum of the product of a weighting factor and time when a building is occupied. In this study, the value of $P P D_{w c}$ is computed in every occupied minute and the result is reported in hours. $P P D_{w c}$ is computed by

$$
P P D_{w c, k}=\sum_{j=1}^{o m}\left(w f_{j} \cdot t_{j}\right) \text { for } k=1, \ldots, n,
$$

where:

$n$ is the number of alternatives;

$w f_{j}$ is the weighting factor in each occupied minute;

om is the total number of occupied minutes; and $t_{j}$ is the time step, $1 \mathrm{~min}$.

The weighting factor is computed by 
where:

$$
w f_{j}=\left\{\begin{array}{ll}
\frac{P P D_{\text {actualPMV }}}{P P D_{\text {PMVlimit }}}, & |P M V|>\left|P M V_{\text {limit }}\right| \\
1 & , P M V=P M V_{\text {limit }} \\
0 & ,|P M V|<\left|P M V_{\text {limit }}\right|
\end{array},\right.
$$

$P P D_{\text {actualPMV }}$ is the $P P D$ corresponding to the actual $P M V$; and $P P D_{P M V l i m i t}$ is the $P P D$ corresponding to $P M V_{\text {limit }}$.

\section{Priorities from Performance Data}

The results of applying Eq. (1.3), Eq. (1.4), and Eq. (1.10) to the performance data for each residential EMCA are shown in Table 12. In this document, Table 12 is referred to as the Performance Table. The values in the Performance Table are used to derive priorities for each residential EMCA relative to the criteria.

Table 12. EMCA Performance Summary

\begin{tabular}{|c|c|c|c|}
\hline Residential EMCA & $\begin{array}{l}\text { Total Energy } \\
\left(\boldsymbol{E}_{\text {total }}\right)[\mathbf{k W h}]\end{array}$ & $\begin{array}{l}\text { Total Cost } \\
\left(\boldsymbol{C}_{\text {total }}\right)[\mathbf{\$}]\end{array}$ & $\begin{array}{l}\text { Discomfort Index } \\
\left(\boldsymbol{P P D}_{\boldsymbol{w c}}\right)[\mathbf{h}]\end{array}$ \\
\hline 1 & 5605 & 901 & 9 \\
\hline 2 & 5588 & 880 & 339 \\
\hline 3 & 5484 & 847 & 1176 \\
\hline 4 & 5762 & 918 & 222 \\
\hline 5 & 5882 & 938 & 0 \\
\hline 6 & 6589 & 1050 & 37 \\
\hline
\end{tabular}

Having computed the total energy consumption $\left(E_{\text {total }}\right)$, cost of consuming energy $\left(C_{\text {total }}\right)$, and the discomfort index $\left(P P D_{w c}\right)$ for all residential EMCAs, the next step is to compute a set of relative priorities when alternatives are pairwise compared. To compute these priorities, an algorithm was developed to first map each column of the Performance Table to the Intensity of Importance in Table 1 then form an MPC using the derived quantified judgements $a_{i j}$ in matrix A. Using AHP's standard procedure described in Sec. 2 on matrix A will result in relative priorities (a set of weights) with respect to criteria along with $\lambda_{\max }, C I$, and $C R$. When creating the MPC, the following main assumptions form the basis of the computations:

1. Lower energy consumption is desired over higher energy consumption;

2. Lower monetary cost is desired over higher cost; and

3. More comfortable environment is desired over less comfortable environment.

The following steps describe the algorithm for computing priorities:

1. Define scale factors for energy $\left(S_{E f}\right)$, cost $\left(S_{C f}\right)$, and discomfort $\left(S_{D f}\right)$. Let $C_{s c a l e}$ represent the AHP's Intensity of Importance shown in Table 1.

$$
S_{E f}=\left(\max \left(C_{\text {scale }}\right)-\min \left(C_{\text {scale }}\right)\right) /\left(\eta_{\max }-\eta_{\text {min }}\right),
$$


where $\eta_{\max }=\max \left(\left\{E_{\text {total }, k}: k=1, \ldots, n\right\}\right)$ and $\eta_{\min }=\min \left(\left\{E_{\text {total }, k}: k=1, \ldots, n\right\}\right)$.

$$
S_{C f}=\left(\max \left(C_{\text {scale }}\right)-\min \left(C_{\text {scale }}\right)\right) /\left(v_{\text {max }}-v_{\text {min }}\right),
$$

where $v_{\max }=\max \left(\left\{C_{\text {total }, k}: k=1, \ldots, n\right\}\right)$ and $v_{\min }=\min \left(\left\{C_{\text {total }, k}: k=1, \ldots, n\right\}\right)$.

$$
S_{D f}=\left(\max \left(C_{\text {scale }}\right)-\min \left(C_{\text {scale }}\right)\right) /\left(\mu_{\max }-\mu_{\min }\right),
$$

where $\mu_{\max }=\max \left(\left\{P P D_{w c, k}: k=1, \ldots, n\right\}\right)$ and $\mu_{\min }=\min \left(\left\{P P D_{w c, k}: k=1, \ldots, n\right\}\right)$.

For instance, using Eq. (1.12), the $S_{E f}$ for the values in $E_{\text {total }}$ (given in Table 12) is approximately 0.007 .

2. Map energy consumption $\left(M_{E}\right)$, cost $\left(M_{C}\right)$, and discomfort $\left(M_{D C}\right)$ to $C_{\text {scale }}$ to create a vector of preferences, rounded to the nearest integer

$$
\begin{gathered}
M_{E, k}=\operatorname{round}\left(\left(\eta_{\max }-E_{\text {total }, k}\right) \times S_{E f}+\min \left(C_{\text {scale }}\right)\right), \forall k=1, \ldots, n \\
M_{C, k}=\operatorname{round}\left(\left(v_{\max }-C_{\text {total }, k}\right) \times S_{C f}+\min \left(C_{\text {scale }}\right)\right), \forall k=1, \ldots, n \\
M_{D C, k}=\operatorname{round}\left(\left(\mu_{\max }-P P D_{w c, k}\right) \times S_{D f}+\min \left(C_{\text {scale }}\right)\right), \forall k=1, \ldots, n .
\end{gathered}
$$

For instance, using Eq. (1.15), mapping the values in $E_{\text {total }}$ (given in Table 12) to $C_{\text {scale }}$ resulted in $M_{E}=[8,8,9,7,6,1]$.

3. Find the differences between each element of $M_{E}, M_{C}$, and $M_{D C}$ with respect to all other elements of the same vector. The result is an $n \times n$ matrix of the form $D_{E}\left(d_{i j}\right), D_{C}\left(d_{i j}\right)$, and $D_{D C}\left(d_{i j}\right)$. More explicitly

Let $d$ represent a vector of mapped preferences (i.e., $M_{E}$ )

$$
d_{i j}=d(i)-d(j)
$$

and

$$
D(i, j)=\left[\begin{array}{cccc}
d_{11} & d_{12} & \cdots & d_{1 n} \\
d_{21} & d_{22} & \cdots & d_{2 n} \\
\vdots & \vdots & ::: & \vdots \\
d_{n 1} & d_{n 2} & \cdots & d_{n n}
\end{array}\right],
$$

where $n$ is the number of elements in $d$. For instance, finding the differences between each element of vector $M_{E}$ results in the matrix $D_{E}\left(d_{i j}\right)$ 


$\begin{array}{ccccccc} & \text { EMCA1 } & \text { EMCA2 } & \text { EMCA3 } & \text { EMCA4 } & \text { EMCA5 } & \text { EMCA6 } \\ \text { EMCA1 } & 0 & 0 & -1 & 1 & 2 & 7 \\ \text { EMCA2 } & 0 & 0 & -1 & 1 & 2 & 7 \\ D_{E}(i, j)=\text { EMCA3 } & 1 & 1 & 0 & 2 & 3 & 8 \\ \text { EMCA4 } & -1 & -1 & -2 & 0 & 1 & 6 \\ \text { EMCA5 } & -2 & -2 & -3 & -1 & 0 & 5 \\ \text { EMCA6 } & -7 & -7 & -8 & -6 & -5 & 0\end{array}$.

The first row of $D_{E}(1, j)$ for $j=1,2, \ldots, 6$ represents the differences between the first element of $M_{E}$ (8 in this case) and all other elements of $M_{E}$, including the first element itself. $D_{C}\left(d_{i j}\right)$ and $D_{D C}\left(d_{i j}\right)$ are determined in a similar manner.

4. In the AHP framework, no MPC can contain any values $\left(d_{i j}\right)$ that are less than or equal to zero. Since the $D_{E}\left(d_{i j}\right)$ matrix contains entries that are less than or equal to zero, the results from step 3 needs to be modified. Let $f_{i j}$ represent the modified entries replacing $d_{i j}$ and $F(i, j)$ replacing $D(i, j)$, where

$$
f_{i j}=\left\{\begin{array}{l}
d_{i j}+1, \text { if } d_{i j} \geq 0 \\
\frac{1}{\left|d_{i j}-1\right|}, \text { if } d_{i j}<0
\end{array},\right.
$$

and the new matrix is

$$
F(i, j)=\left[\begin{array}{cccc}
f_{11} & f_{12} & \cdots & f_{1 n} \\
f_{21} & f_{22} & \cdots & f_{2 n} \\
\vdots & \vdots & \vdots: \vdots & \vdots \\
f_{n 1} & f_{n 2} & \cdots & f_{n n}
\end{array}\right] .
$$

\begin{tabular}{|c|c|c|c|c|c|c|}
\hline & $E M C A 1$ & EMCA2 & EMCA3 & EMCA4 & EMCA5 & EMCA6 \\
\hline EMCA1 & 1 & 1 & $1 / 2$ & 2 & 3 & 8 \\
\hline EMCA2 & 1 & 1 & $1 / 2$ & 2 & 3 & 8 \\
\hline$F_{E}(i, j)=E M C A 3$ & 2 & 2 & 1 & 3 & 4 & 9 \\
\hline EMCA4 & $1 / 2$ & $1 / 2$ & $1 / 3$ & 1 & 2 & 7 \\
\hline EMCA5 & $1 / 3$ & $1 / 3$ & $1 / 4$ & $1 / 2$ & 1 & 6 \\
\hline EMCA6 & $1 / 8$ & $1 / 8$ & $1 / 9$ & $1 / 7$ & $1 / 6$ & 1 \\
\hline
\end{tabular}

The process in step 4 results in $F_{E}(i, j)$ given below

$F(i, j)$ is an MPC that satisfies Rule 1 and Rule 2 described in Section 2 and reflects the derived objective judgments obtained from the performance data documented in the Performance Table 
for each alternative residential EMCA with respect to the energy, cost, and comfort criteria. Applying AHP's standard eigenvector and eigenvalue methods to $F(i, j)$, the relative priorities for each alternative with respect to the criteria, as well as consistency metrics $C I$ and $C R$, are computed. For instance, the relative priorities of residential EMCAs with respect to the energy criterion, using $F_{E}(i, j)$, is given in Table 13.

\section{Table 13. Priorities and Consistency Metrics}

\begin{tabular}{|c|c|c|}
\hline Residential EMCAs & $\begin{array}{c}\text { Priorities with respect } \\
\text { to energy criterion } \\
\text { and consistency metrics }\end{array}$ & \\
\hline 1 & 0.21 & \multirow{3}{*}{ Priorities } \\
\hline 2 & 0.21 & \\
\hline 3 & 0.34 & \multirow{3}{*}{ Consistency } \\
\hline 4 & 0.13 & \\
\hline 5 & 0.08 & \\
\hline 6 & 0.02 & \\
\hline$\lambda_{\max }$ & 6.15 & \\
\hline$C I$ & 0.03 & \\
\hline$C R$ & 0.03 & \\
\hline
\end{tabular}

In Table 13, residential EMCA3 has the highest priority with respect to the energy criterion compared to other alternatives, which is consistent with our assumption that less energy consumption is more desirable. The $C R$ value of $3 \%$ is less than the recommended consistency of $10 \%$, suggesting that the judgments for comparing alternatives are consistent. 


\section{Overall Scores}

Having computed priorities of criteria with respect to the goal $(w g)$ and priorities of each alternative with respect to criteria $\left(p_{a}\right)$, the overall score for each alternative with respect to the goal is computed by Eq. (1.2). Recall that the priorities of criteria with respect to the goal along with consistency metrics were given in Table 8. The priorities $\left(p_{a}\right)$ for each alternative with respect to the criteria for residential EMCAs and the consistency metrics are given in Table 14. For example, priorities of residential EMCA1 with respect to the energy, cost, and comfort criteria is $p_{a}=[0.21,0.16,0.26]$.

Table 14. Priorities and Consistency Metrics

\begin{tabular}{|c|c|c|c|c|}
\hline $\begin{array}{c}\text { Residential EMCAs } \\
\text { and consistency metrics }\end{array}$ & Energy & Cost & Comfort & \\
\hline 1 & 0.21 & 0.16 & 0.26 & \\
\hline 2 & 0.21 & 0.25 & 0.10 & \multirow{3}{*}{ Priorities } \\
\hline 3 & 0.34 & 0.38 & 0.02 & \\
\hline 4 & 0.13 & 0.11 & 0.10 & \\
\hline 5 & 0.08 & 0.07 & 0.26 & \multirow{2}{*}{ Consistency } \\
\hline 6 & 0.02 & 0.02 & 0.26 & \\
\hline$\lambda_{\max }$ & 6.15 & 6.22 & 6.12 & \\
\hline$C I$ & 0.03 & 0.04 & 0.02 & \\
\hline$C R$ & 0.03 & 0.03 & 0.02 & \\
\hline
\end{tabular}

The overall scores for residential EMCAs with respect to the goal are calculated using Eq. (1.2) and shown in Table 15.

Table 15. The Overall Scores

\begin{tabular}{|c|c|}
\hline Residential EMCAs & Overall scores (ranking) \\
\hline 1 & 0.19 \\
\hline 2 & 0.21 \\
\hline 3 & 0.28 \\
\hline 4 & 0.11 \\
\hline 5 & 0.12 \\
\hline 6 & 0.09 \\
\hline
\end{tabular}

Based on the overall scores in Table 15, residential EMCA3 is the most desirable alternative with respect to the overall goal reflecting user's very strong preference in an alternative that saves the most money (lowest cost) followed by a strong desire for comfort over energy savings, and weak preference for comfort over cost. The relationship between alternatives, criteria, and the goal are shown in Figure 10. It shows the problem hierarchy, an example of computed priorities for two residential EMCAs, and the overall scores (ranking) for all residential EMCAs. 


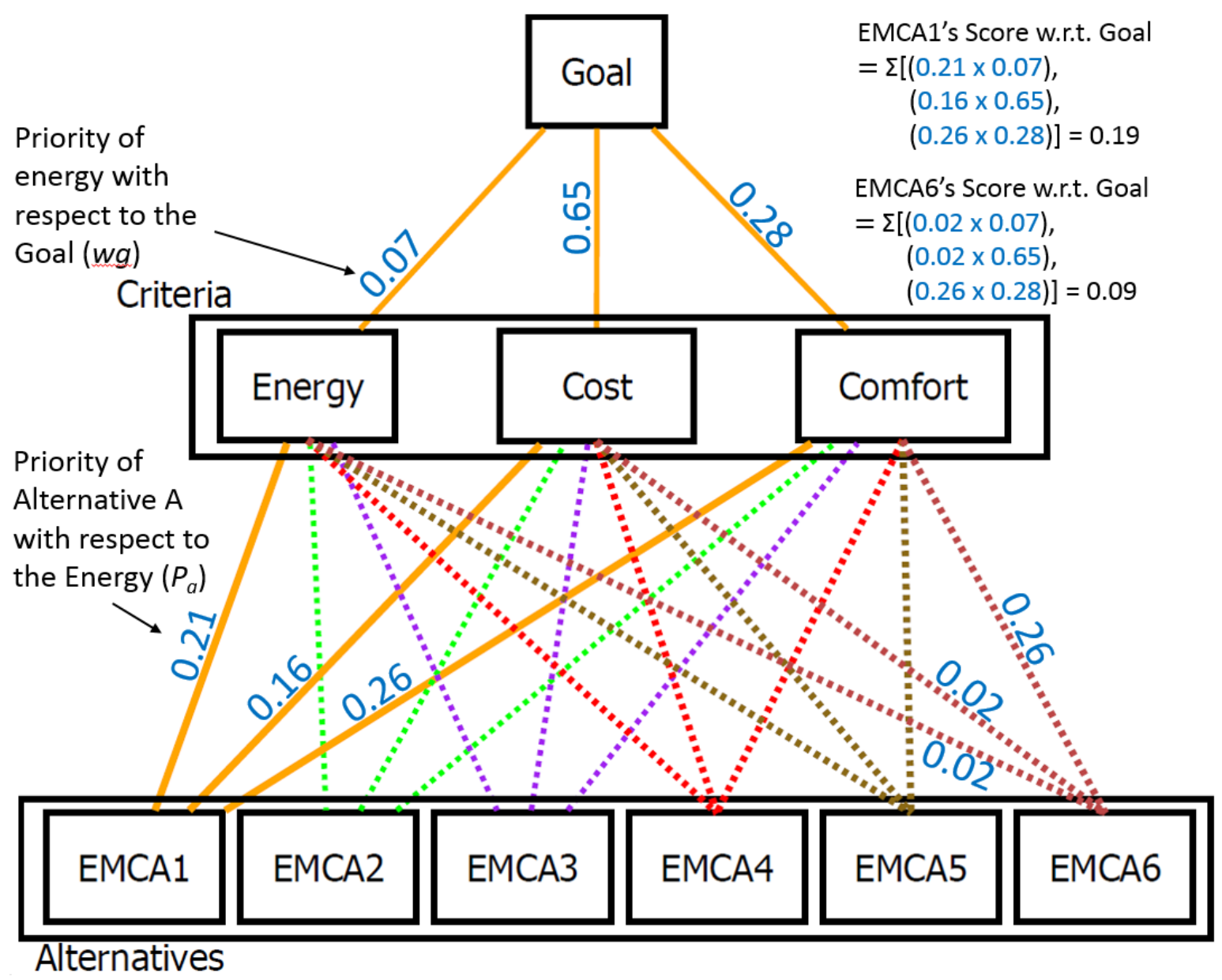

Figure 10. Summary figure showing the problem hierarchy, priorities and the overall scores for each alternative with respect to the goal

As previously mentioned, based on the performance data and user preferences, residential EMCA3 was ranked the highest by the AE. Depending on user preferences, a different algorithm other than residential EMCA3 can be ranked the highest by the AE. Recall that user preferences can only impact priorities of criteria with respect to the goal. For example, assume that a user conveys a very strong desire in an alternative that provides the most comfort over cost, a strong preference for comfort over energy consumption, but a weak preference for energy consumption over cost. These preferences are captured by the AE in inputs fields of Figure 7 as following:

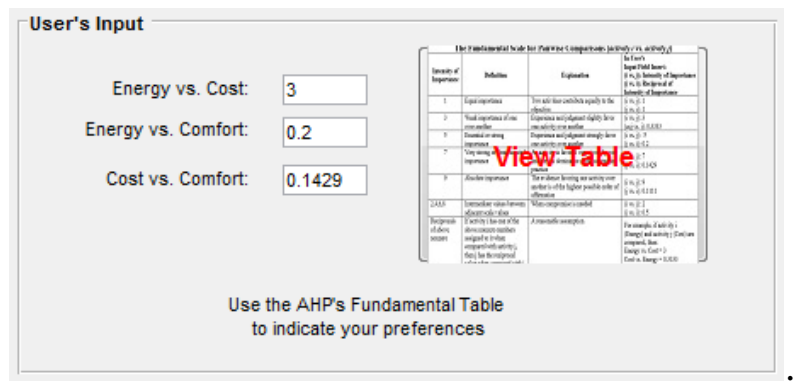


The AE forms the corresponding MPC for pairwise comparisons between criteria as shown in Table 16. It also calculates priorities for criteria with respect to the goal and the overall scores based on the new priorities.

Table 16. MPC for Capturing User Preferences

\begin{tabular}{|l|c|c|c|}
\hline & Energy & Cost & Comfort \\
\hline Energy & 1 & 3 & $1 / 5$ \\
\hline Cost & $1 / 3$ & 1 & $1 / 7$ \\
\hline Comfort & 5 & 7 & 1 \\
\hline
\end{tabular}

The $C R$ value of $5.7 \%$ suggests that the user's judgments in Table 16 were consistent and the overall scores for residential EMCAs with respect to the goal are given in Table 17.

Table 17. The Overall Scores

\begin{tabular}{|c|c|}
\hline Residential EMCAs & Overall scores (ranking) \\
\hline 1 & 0.24 \\
\hline 2 & 0.13 \\
\hline 3 & 0.11 \\
\hline 4 & 0.11 \\
\hline 5 & 0.21 \\
\hline 6 & 0.20 \\
\hline
\end{tabular}

The overall scores in Table 17 show that residential EMCA1 is the most desirable alternative followed by residential EMCA5. The top two choices both offer similar comfort levels (lower discomfort index), however, residential EMCA1 is the top-ranked because it consumes less energy and has a lower cost compared to residential EMCA5.

\section{Limitations}

The AE has potential limitations that are broadly categorized into time interval match between data, software implementation, and scalability. The time interval for measuring electricity consumption and the time interval for pricing must align to calculate cost. The AE software implementation was designed for one-minute data intervals for calculating thermal comfort metrics. It also assumes that mean radiant temperature is equal to the indoor dry-bulb temperature. This assumption may not be valid for residential homes where the indoor temperatures are significantly impacted by direct solar radiation. Although the AE has been successfully demonstrated for a single-family house, applying the assessment concept to other building types such as offices, stores, and multi-zone buildings would be difficult without significant modifications. It would be necessary to consider the fact that different zones will have different results. Simply computing totals is unlikely to be satisfactory because some zones may be more important or impact more occupants than others.

\section{Conclusion}

For homes to become active participants in a smart grid, intelligent control algorithms are needed to facilitate autonomous interactions that take homeowner preferences into consideration. Many control algorithms for demand response have been proposed in the 
literature. Comparing the performance of these algorithms has been difficult because each algorithm makes different assumptions or considers different scenarios, i.e., peak load reduction or minimizing cost in response to the variable price of electricity. This work demonstrates a flexible assessment framework using the Analytical Hierarchy Process to compare and rank residential energy management control algorithms. The framework is a hybrid mechanism that derives a ranking from a combination of subjective user input representing preferences, and object data from the algorithm performance related to energy consumption, cost and comfort. The Analytical Hierarchy Process results in a single overall score used to rank the alternatives. The approach is illustrated by applying the assessment process to six residential energy management control algorithms. The assessment and ranking of residential EMCAs was successfully demonstrated, showing that residential EMCA3 was ranked the highest. 


\section{Acknowledgments}

The authors wish to thank everyone involved in the Net Zero Residential Test Facility project. Special thanks are extended to Dan Veronica, and Amanda Pertzborn. 


\section{References}

[1] EIA, “Monthly Energy Review,” Table 7.6 Electricity End Use, U.S. Energy Information Administration, 2018. [Online]. Available:

https://www.eia.gov/totalenergy/data/monthly/pdf/sec7_19.pdf. [Accessed: 13-Mar2018].

[2] EIA, “Annual Energy Outlook 2018 with projections to 2050,” Table 4: Residential Sector Key Indicator and Consumption, U.S. Energy Information Administration, 2018. [Online]. Available: https://www.eia.gov/outlooks/aeo/pdf/AEO2018.pdf. [Accessed: 13-Mar-2018].

[3] "Energy Independence and Security Act of 2007," United States, Public Law 110-140, 2007.

[4] NIST, "NIST Framework and Roadmap for Smart Grid Interoperability Standards, Release 3.0,” NIST Spec. Publ. 1108R3, 2014.

[5] U.S. Department of Energy, "Benefits of Demand Response in Electricity Markets and Recommendations for Achieving Them,” 2006.

[6] J. S. Vardakas, N. Zorba, and C. V. Verikoukis, “A Survey on Demand Response Programs in Smart Grids: Pricing Methods and Optimization Algorithms,” IEEE Commun. Surv. Tutorials, vol. 17, no. c, pp. 1-1, 2014.

[7] R. Deng, Z. Yang, M.-Y. Chow, and J. Chen, "A Survey on Demand Response in Smart Grids: Mathematical Models and Approaches,” IEEE Trans. Ind. Informatics, vol. 11, no. 3, pp. 1-1, 2015.

[8] P. Siano, “Demand response and smart grids-A survey,” Renew. Sustain. Energy Rev., vol. 30, pp. 461-478, 2014.

[9] C. Chen, S. Kishore, and L. V. Snyder, “An innovative RTP-based residential power scheduling scheme for smart grids,” ICASSP, IEEE Int. Conf. Acoust. Speech Signal Process. - Proc., pp. 5956-5959, 2011.

[10] A. H. Mohsenian-Rad and A. Leon-Garcia, "Optimal residential load control with price prediction in real-time electricity pricing environments,” IEEE Trans. Smart Grid, vol. 1, no. 2, pp. 120-133, 2010.

[11] M. Avci, M. Erkoc, A. Rahmani, and S. Asfour, "Model predictive HVAC load control in Buildings using real-time electricity pricing," Energy Build., vol. 60, pp. 199-209, 2013.

[12] A. Afram, F. Janabi-sharifi, A. S. Fung, and K. Raahemifar, “Artificial neural network ( ANN ) based model predictive control ( MPC ) and optimization of HVAC systems : A state of the art review and case study of a residential HVAC system,” Energy Build., vol. 141, pp. 96-113, 2017.

[13] J. H. Yoon, R. Baldick, and A. Novoselac, "Demand response control of residential HVAC loads based on dynamic electricity prices and economic analysis,” Sci. Technol. Built Environ., vol. 22, no. 6, pp. 705-719, 2016.

[14] T. Cui, S. Chen, Y. Wang, Q. Zhu, S. Nazarian, and M. Pedram, “Optimal coscheduling of HVAC control and battery management for energy-efficient buildings considering state-of-health degradation,” Proc. Asia South Pacific Des. Autom. Conf. ASP-DAC, vol. 25-28-Janu, pp. 775-780, 2016.

[15] F. Nägele, T. Kasper, and B. Girod, “Turning up the heat on obsolete thermostats: a simulation-based comparison of intelligent control approaches for residential heating systems,” Renew. Sustain. Energy Rev., vol. 75, pp. 1254-1268, 2017. 
[16] J. Lu, T. Sookoor, V. Srinivasan, G. Gao, B. Holben, J. Stankovic, E. Field, and K. Whitehouse, "The Smart Thermostat: Using Occupancy Sensors to Save Energy in Homes,” Proc. ACM SenSys, vol. 55, pp. 211-224, 2010.

[17] K. X. Perez, M. Baldea, and T. F. Edgar, "Integrated smart appliance scheduling and HVAC control for peak residential load management,” Proc. Am. Control Conf., vol. 2016-July, pp. 1458-1463, 2016.

[18] B. Urban and K. Roth, "A Data-Driven Framework for Comparing Residential Thermostat Energy Performance,” Fraunhofer Center for Sustainable Energy Systems, Final Report | Co-Developed with NEST, 2014.

[19] J. Iwaro, a Mwasha, R. Williams, and R. Zico, “An Integrated Criteria Weighting Framework for the sustainable performance assessment and design of building envelope,” Renew. Sustain. Energy Rev., vol. 29, pp. 417-434, 2014.

[20] C. J. Hopfe, G. L. M. Augenbroe, and J. L. M. Hensen, "Multi-criteria decision making under uncertainty in building performance assessment,” Build. Environ., vol. 69, pp. 81-90, 2013.

[21] T. L. Saaty, Multicriteria Decsion Making: The Analytic Hierarchy Process. University of Pittsburgh, 1988.

[22] S. D. Pohekar and M. Ramachandran, “Application of multi-criteria decision making to sustainable energy planning - A review,” Renew. Sustain. Energy Rev., vol. 8, no. 4, pp. 365-381, 2004.

[23] G. A. Norris and H. E. Marshall, "Multiattribute decision analysis method for evaluating buildings and building systems.," NIST Tech. Note 5663, 1995.

[24] O. S. Vaidya and S. Kumar, "Analytic hierarchy process: An overview of applications,” Eur. J. Oper. Res., vol. 169, no. 1, pp. 1-29, 2006.

[25] ASTM, "Standard Practice for Applying Analytical Hierarchy Process ( AHP ) to Multiattribute Decision Analysis of Investments Related to Buildings and Building Systems 1,” 2016.

[26] J. Lofberg, "YALMIP : a toolbox for modeling and optimization in MATLAB," in 2004 IEEE International Conference on Robotics and Automation (IEEE Cat. No.04CH37508), 2004, pp. 284-289.

[27] F. Omar, "A Residential Energy Control Algorithm Assessment Tool for Smart Grid : Multi-Criteria Decision Making Using the Analytical Hierarchy Process,” Ph.D. Dissertation, 2019. [Online]. Available: https://doi.org/10.18130/v3-d6fh-nj31.

[28] E. Balke, G. Nellis, S. Klein, H. Skye, V. Payne, and T. Ullah, "Detailed energy model of the National Institute of Standards and Technology Net-Zero Energy Residential Test Facility: Development, modification, and validation,” Sci. Technol. Built Environ., vol. 0, no. 0, pp. 1-14, 2017.

[29] F. Omar and S. T. Bushby, "Simulating Occupancy in The NIST Net-Zero Energy Residential Test Facility,” NIST Tech. Note 1817, 2013.

[30] S. Carlucci and L. Pagliano, "A review of indices for the long-term evaluation of the general thermal comfort conditions in buildings,” Energy Build., vol. 53, pp. 194-205, 2012.

[31] ISO 7730, "Erogonomics of the Thermal Environment - Analytical Determination and Interpretation of Thermal Comfort Using Calculation of the PMV and PPD Indices and Local Thermal Comfort Criteria,” 2005.

[32] ASHRAE, "Standard 55-2010. Thermal Environmental Conditions for Human 
Occupancy.Atlanta: American Society of Heating Refrigerating and Air Conditioning Engineers,” Atlanta, USA, 2010.

[33] N. Walikewitz, B. Jänicke, M. Langner, F. Meier, and W. Endlicher, "The difference between the mean radiant temperature and the air temperature within indoor environments: A case study during summer conditions,” Build. Environ., vol. 84, pp. 151-161, 2015.

[34] M. Langner, K. Scherber, and W. R. Endlicher, "Indoor heat stress: An assessment of human bioclimate using the UTCI in different buildings in Berlin," DIE ERDE, vol. 144, no. 3-4, pp. 260-273, 2013.

[35] L. Ng, "A Software Program for Calculating PMV and PPD." Private Communications, National Institute of Standards and Technology, MD, 2017.

[36] A. Persily and L. de Jonge, "Carbon dioxide generation rates for building occupants," Indoor Air, vol. 27, no. 5, pp. 868-879, 2017. 